\title{
Infrared detection of ore variability that influences the environmental risks during perlite mining and processing
}

\author{
L. A. Adriana Guatame-García ${ }^{1}$ (i) $\cdot$ M. W. N. Mike Buxton ${ }^{1}$
}

Received: 29 May 2017/ Accepted: 16 October 2017/Published online: 30 October 2017

(C) The Author(s) 2017. This article is an open access publication

\begin{abstract}
In the mining of perlite deposits, controlling the generation of fine particles and the concentration of metals is of outstanding importance to meet the environmental and market requirements. Particle size and chemical purity are conventionally manipulated during the processing of the ore to achieve high product specifications. However, the current practices do not consider a proactive approach that focuses in the in-pit characterisation of the ore that would minimise the environmental impact and optimise the mining process since its early stages. This paper presents a method for the in-pit detection of the perlite ore variability that is related to the generation of fine particles and the elevated concentration of metals. Particle size and chemical purity showed to be dependent on the mineralogical variations of the ore, specifically opal and montmorillonite. Using a portable infrared spectrometer, an index that establishes the relative proportions of these minerals in the perlite ore was created. Such index provided insight into the correlation between mineralogy, fine particles and concentration of metals. Consequently, the index could be used not only for mineralogical determination but also as a predictor of the presence of the main impurities in the perlite ore. These results can be implemented in perlite mining to reduce the generation of waste and can influence the production of high-quality perlite products.
\end{abstract}

Keywords Perlite $\cdot$ Infrared spectroscopy $\cdot$ Mining · Environmental risk - Chemical impurities - Fine particles

\footnotetext{
L. A. Adriana Guatame-García

1.a.guatame-garcia@tudelft.nl

1 Resource Engineering, Faculty of Civil Engineering and Geosciences, Delft University of Technology, P.O. Box 5048, 2600 GA Delft, The Netherlands
}

\section{Introduction}

Perlite is a versatile material with unique properties, and it is used in numerous industrial applications. In particular, perlites chemical inertness and expansion capabilities make it a preferred filter aid in the food, pharmaceutical and chemical industries (Shackley and Allen 1992). Natural perlite is a form of hydrated volcanic glass emplaced in the top of high-silica rhyolite lava domes (Allen 1988; Fink 1983). In such an environment, the mineralogy and the chemistry of the ore body vary according to the geological features of the perlite deposit (Noh and Boles 1989). Examples of such variations are those caused by hydrothermal alteration, as described by Clarke (1989) and Silberman and Berger (1985). The particular characteristics of the deposit have a direct impact on the mining of perlite deposits, by affecting the generation of mine waste and the quality of commercial perlite products. Therefore, it is fundamental to understand and control the variability of the ore since the early stages of the mining activities.

The environmental regulations and the perlite market conditions define the quality parameters that mining companies must meet. Authorities such as the USEPA (1995) and USPC (2012) describe the fine particles generated during mineral processing and the content of metals in the ore as potential environmental risks and therefore are considered as cost penalties, which must be below certain thresholds. The fine particles are generally treated as nuisance dust; what is more, evidence provided by Elmes (1987) and Maxim et al. (2014) suggests that in large amounts, these particles represent a factor of air pollution and a potential health risk for workers. Regarding the chemical purity, even though perlite is deemed to be an inert material, it has been mentioned before that the chemical composition of the ore can still be altered by the 
particular geological features of the deposit, which might result in an enrichment of elements that ultimately contaminate the ore.

Due to the simplicity of the mining value chain and the relative abundance of chemically pure perlite deposits, there has been limited systematic research into the opportunities for optimisation in the mining and processing of perlite. However, Bennett (2013) remarked that the increasing demand for perlite products, as well as the development of novel applications, might result in a depletion of reserves. Therefore, new challenges in the mining and processing of perlite ores are arising. Strategies that aim for early detection of potential environmental risks involved in perlite mining and processing are of considerable interest for the industry. For doing so, the identification of the contaminants, such as fine particles and metals, can be addressed from a mineralogical perspective, by analysing the composition of the ore and its different size fractions. The approach involves identification of the mineralogical content of the different size fractions of the perlite, and the determination of the metals bearing mineral phases. Sensor technologies that allow on-site and realtime mineralogical characterisation of the ore would aid in the in-pit identification of perlite impurities, assisting the decision-making process during mineral extraction and processing.

The purpose of this study is to create a method for characterising perlite ores in-pit, with a focus on the determination of the likelihood of generating fine particles, and the assessment for the presence of chemical impurities. This paper presents the characteristics of perlite samples from a mine in the Dikili area in west-Turkey regarding particle size analysis, chemistry and mineralogy. Infrared spectroscopy was used to create a mineralogical index that estimates the proportion of the mineral content in the ore, which can be used to determine the ore variability in relation to the environmental risks. The paper also discusses the potential for implementing the results of this work in realistic in-pit conditions.

\section{Perlite deposits in western Turkey}

The Dikili perlite deposits (western Turkey) are associated with the Western Anatolian Miocene volcanism. In this area, the widespread magmatism related to the tectonic evolution produced a variety of plutonic and volcanic rocks. The volcanic associations range from dacite-rhyolite to basaltic andesites (Karacik et al. 2007). During the Late Miocene-Early Pliocene, a tectonic extensional regime favoured the extrusion of rhyolitic domes and basaltic trachyandesite lava dykes, which are structurally controlled along NE-SW trending fault systems. At the top of the rhyolitic domes, obsidian and perlite are common. In such environment, the perlite genesis is the result of the interaction between volcanic glass with fluids from hydrothermal or meteoric origin, leading to the hydration of the silica phase, forming opal, in paragenesis with smectites, zeolites, quartz and feldspars (Allen 1988; Fink 1983; Noh and Boles 1989). Depending on the glass' alteration, different perlite facies range from classical, with characteristical onion skin texture that indicates low degree of alteration, to granular and finally pumiceous, as the highly altered facies (Barker and Santini 2006).

The volcanic activity and active tectonics in western Turkey served as a suitable environment for the presence of metal enrichment in the perlite. This environment enabled the circulation of hydrothermal fluids through major faults and fracture zones that interacted with the perlite, leading to the adsorption of metals at the glass surface (Baba and Sozbilir 2012; Petit et al. 1990). One scenario that might have permitted such interaction was the process of perlitisation of the volcanic glass, where the alteration fluids could have carried metals. Another scenario was the presence of fluids at a stage posterior to the perlite formation, where the emplacement of younger epithermal mineralisation systems, such as those presented by Yilmaz (2002), cross-cut the perlite domes. These intrusions generated new hydrothermal pathways that altered the perlite bodies, creating outcrop-scale alteration halos, following the patterns described by Yanev (2008). In both scenarios, the attribution of elevated contents of metals is given to ascending hydrothermal fluids of magmatic origin and to the percolation of ground water that leached metals from the host rocks by oxidation of sulphides (Baba and Sozbilir 2012). Such metals are those commonly present in epithermal environments, e.g. As, $\mathrm{Fe}, \mathrm{Zn}, \mathrm{Pb}, \mathrm{Cu}, \mathrm{Nd}, \mathrm{Co}$, $\mathrm{Hg}$ and $\mathrm{Sb}$, which are usually associated with $\mathrm{Mn}, \mathrm{Ba}, \mathrm{Rb}$ and Ti (Clarke 1989; Silberman and Berger 1985).

\section{Environmental risks associated with perlite ores}

Perlite filter aids used for filtering liquids in the beverage, food and pharmaceutical industries must not impart any colours or odours, or contain any contaminant that could be hazardous to human or animal health or the environment. To deem perlite products as safe for their intended use, they should meet the standards listed by the Food and Agriculture Organization of the United Nations (FAO 2006), the Food Chemicals Codex (USPC 2012), the Oenological Codex (OIV 2017) and other market-specific purity acceptance criteria set by perlite customers. As previously mentioned, depending on the particularities of the geological setting, the perlite body can be exposed to 
potential contaminants that affect the chemical inertness, and therefore, the acceptability for the use of perlite filters.

Along with chemical inertness, the expansion capability is the most interesting property of perlite. The production of lightweight filter aids consists of open-pit mining, particle size reduction (comminution and sizing) and thermal expansion. In this last step, the ore is thermally treated at temperatures between 800 and $1100^{\circ} \mathrm{C}$, causing expansion up to twenty times the original particle size (Blunt 1994; Shackley and Allen 1992). Stein and Murdock (1955) pointed out that the success of the expansion process greatly depends upon the plants capacity to generate particles conforming to the specifications for size distribution, which normally varies between $50 \mu \mathrm{m}$ and $5.00 \mathrm{~mm}$. For this reason, comminution (crushing and milling) and sizing are the main steps before thermal expansion. However, since perlite is quite friable, the reduction of the particle size inevitably produces large quantities of dust and excessively fine material that, in most of the cases, are dumped as a waste (Ray et al. 2007). Davidson et al. (2005) reviewed evidence that shows that particulate material generated during the mineral processing is a matter of concern since it greatly contributes to air pollution in mining regions and has an influence on human health. Nevertheless, Elmes (1987) mentioned that the particles produced during perlite comminution could be treated as a nuisance dust since they do not contain quartz or fibrous minerals. Moreover, Cooper and Sargent (1986) indicated that perlite dust does not pose a significant health risk for workers. However, more recent studies, such as those conducted by Maisanaba et al. (2015); Maxim et al. (2014); Sampatakakis et al. (2013), suggest that excess of exposure to perlite dust without the necessary protective equipment might result in adverse health effects. In addition, they indicate that the potential impact of the other minerals that are present in the perlite ore should not be underestimated.

The mining style for perlite and the facilities that are commonly available at the processing plants make difficult to monitor the potential environmental risks proactively. The laboratory facilities in the perlite processing plants are rather small and are not capable of performing detailed chemical or mineralogical analyses.

\section{Methods}

\section{Sample collection}

The samples for this study were collected from three different pits in a perlite mine in the Dikili area (west-Turkey). Even though classical and granular perlites are present in the deposit, only classical perlite is sold to the filtration market; therefore, only this perlite type was surveyed.

The samples used for particle size analysis come from Pits 1 and 2. The ore in these pits, which are currently active, is deemed uniform. The samples come from run-ofmine (ROM) stockpiles that normally serve as feed for the processing plant. At each pit, the ore was extracted along cross sections using mobile ripping; the material was then transported to the processing plant where dumps from aleatory parts of the pit were combined and homogenised to form the stockpiles. Three random stockpiles were chosen per pit, from which $5 \mathrm{~kg}$ was collected with a shovel at the centre of the volume of every stockpile. This sample collection strategy, which combines random and clustering sampling, ensures the good representativity of the collected material. In the normal processing operations, the stockpiles are blended before crushing to homogenise the ore. For this study, the samples from every pit were treated separately to identify the ore variability between pits.

In Pit 3, enrichment in chemical impurities was expected due to a local rhyolitic intrusion. For this reason, Pit 3 is not intended for commercial production, but it is used to study the impact of hydrothermal alteration in the ore, which is detrimental to the perlite quality. Therefore, this pit cannot be regarded as representative from the entire volume of the ore, but of undesired ore conditions. The samples were systematically collected in a radius of $10 \mathrm{~m}$ from the vein in two opposite directions (north and south) in segments of $1 \mathrm{~m}$ wide to assess the distribution of the elements of interest and the mineralogical variation of the perlite. The sample set included one additional sample from the rhyolite vein. Figure 1 shows the pit face used for sampling and the location of the samples. The material was collected from the surface of the pit face by ripping with peak and shovel. The naming of the samples corresponds to the location of the sample (north $=\mathrm{N}$, south $=\mathrm{S}$ ) and the distance from the vein.

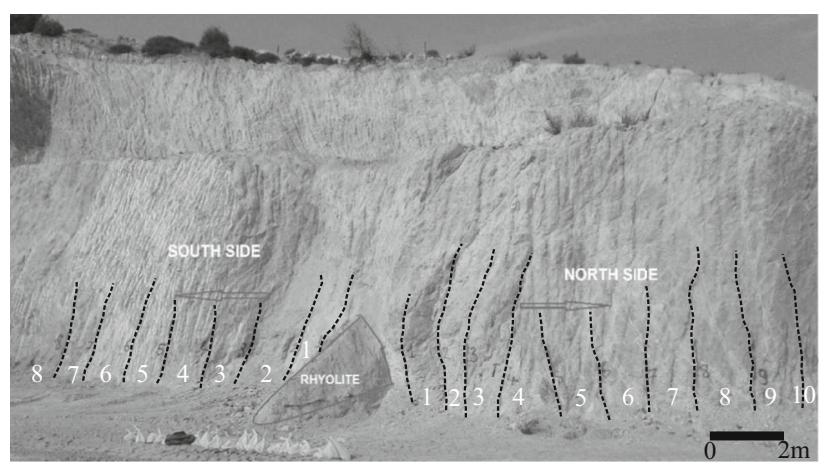

Fig. 1 Mine face of Pit 3, including the samples location 


\section{Mineralogy}

The mineralogical content was estimated using infrared spectroscopy. The selection of the technique was due to its ability to detect amorphous phases of minerals, which provides an advantage for the detection of opaline silica, which is the major constituent in perlite (Chester and Elderfield 1968). Furthermore, the availability of infrared field devices facilitates an in-pit implementation of the results (Thompson et al. 1999). Spectra were first collected in the laboratory for spectral characterisation, and later new spectra were collected using a field portable device to assess the opportunities for on-site implementation. Generally, laboratory data are recorded in wavenumbers $\left(\mathrm{cm}^{-1}\right)$, whereas for field spectroscopy applications the wavelength is recorded in micrometres $(\mu \mathrm{m})$. Since this paper uses both laboratory and field spectra, the units are reported in micrometres with the respective wavenumber in parentheses. The spectral ranges used here follow the conventions set by Gupta (2003) and Hackwell et al. (1996). They are defined as Short-Wave infrared (SWIR), from 1.00 to $2.50 \mu \mathrm{m}\left(10,000-4000 \mathrm{~cm}^{-1}\right)$, and MidWave Infrared (MWIR), from 2.50 to $7.00 \mu \mathrm{m}$ (4000-1429 $\mathrm{cm}^{-1}$ ), and Long-Wave Infrared (LWIR), from 7.00 to $16.00 \mu \mathrm{m}\left(1429-625 \mathrm{~cm}^{-1}\right)$.

Laboratory Attenuated Total Reflectance (ATR) spectra were collected using pressed powders with a Perkin Elmer Spectrum 100 FTIR Spectrometer covering the MWIRLWIR spectrum, with a resolution of $2 \mathrm{~cm}^{-1}$ and 16 scans per sample. Reflectance spectra collected with the field portable spectrometer were measured on loose powders placed in Petri dishes with a Panalytical ASD FieldSpec spectrometer covering the SWIR range, using a contact probe and an internal light source; the spectral resolution was $0.01 \mu \mathrm{m}$, and 50 scans were collected per sample.

In the MWIR-LWIR range, opaline silica can be identified by the strong $\mathrm{Si}-\mathrm{O}$ features at $10.00 \mu \mathrm{m}\left(1000 \mathrm{~cm}^{-1}\right)$, water absorptions at $6.13 \mu \mathrm{m}\left(1631 \mathrm{~cm}^{-1}\right)$ and free-hydroxyl bands between 2.60 and $2.90 \mu \mathrm{m}$ (3846 and $3448 \mathrm{~cm}^{-1}$ ) (Parke 1974). Quartz and feldspars have absorptions in between 9.50 and $13.00 \mu \mathrm{m}$ (1053 and $769 \mathrm{~cm}^{-1}$ ) (Moenke 1974). Clay minerals have characteristic metal-hydroxyl bands around 10.00 and $12.00 \mu \mathrm{m}$ (1000 and $833 \mathrm{~cm}^{-1}$ ) and the free hydroxyls bands around 2.60 and $2.90 \mu \mathrm{m}$ (3846 and $3448 \mathrm{~cm}^{-1}$ ) (Farmer 1974). In the SWIR range, only minerals that bear metal-hydroxyl bonds are identifiable. In opaline silica $(\mathrm{Si}-\mathrm{OH})$ and clay minerals $(\mathrm{Al}-\mathrm{OH})$, this absorption is present around $2.22 \mu \mathrm{m}\left(4505 \mathrm{~cm}^{-1}\right)$. The molecular water has a characteristic absorption at $1.90 \mu \mathrm{m}$ $\left(5263 \mathrm{~cm}^{-1}\right)$ (Hunt 1977).

\section{Particle size}

For particle size analysis, the samples from Pits 1 and 2 were sieved at ten different size fractions. Per every stockpile sample, 600 grammes were fractioned in a laboratory mechanical shaker during $15 \mathrm{~min}$ with a nest of sieves between 6.30 and $0.06 \mathrm{~mm}$. The aperture of the mesh was selected based on the typical particle sizes produced during the perlite processing. The coarser size corresponds to the feed for the comminution, whereas particle gradations between 4.00 and $0.06 \mathrm{~mm}$ correspond to the size fractions generated for different applications. The finest particles $(<0.06 \mathrm{~mm})$ correspond to the dust fraction, which is dumped as a waste. These samples were named as PX-\#, where $\mathrm{x}$ corresponds to the pit source (1 or 2 ), and \# makes reference to the particle size.

\section{Chemical impurities}

The chemical composition of the samples was determined using laboratory X-ray fluorescence. The measurements were collected using a Panalytical Axios Max WD-XRF spectrometer. The major elements were used to validate the mineralogical interpretation, whereas the criteria for selection of the elements regarded as chemical impurities were based on the standards mentioned in "Environmental risks associated with perlite ores" section. Table 1 lists the chemical impurities as well as the accepted maximum concentration level established by the accepted authorities, which is taken as a reference level in this study. The characterisation of the chemical impurities was firstly done in the samples from Pit 3. Then those observations were used to analyse such impurities in the size fraction samples of Pits 1 and 2 .

Table 1 Elements regarded as chemical impurities in perlite products and their respective accepted maximum concentration level as per established by authorities and perlite customers

\begin{tabular}{llll}
\hline Element & Threshold & Element & Threshold \\
\hline $\mathrm{As}$ & $1-12 \mathrm{ppm}$ & $\mathrm{Nd}$ & $20 \mathrm{ppm}$ \\
$\mathrm{Ba}$ & Report & $\mathrm{Ni}$ & $10 \mathrm{ppm}$ \\
$\mathrm{Cd}$ & $1-2 \mathrm{ppm}$ & $\mathrm{Pb}$ & $5-30 \mathrm{ppm}$ \\
$\mathrm{Co}$ & $1 \mathrm{ppm}$ & $\mathrm{Rb}$ & Report \\
$\mathrm{Cr}$ & $5 \mathrm{ppm}$ & $\mathrm{Sb}$ & $2 \mathrm{ppm}$ \\
$\mathrm{Cu}$ & Report & $\mathrm{Se}$ & Report \\
$\mathrm{F}$ & $150 \mathrm{ppm}$ & $\mathrm{Ti}$ & Report \\
$\mathrm{Fe}$ & $300 \mathrm{ppm}$ & $\mathrm{Zn}$ & Report \\
$\mathrm{Hg}$ & $0.1-1.0 \mathrm{ppm}$ & & \\
\hline
\end{tabular}




\section{Results and discussion}

\section{Mineralogical variability of the perlite ore}

The mineralogical variability of the perlite ore was determined using ATR spectroscopy. Figure 2 shows the spectra of representative samples for every pit in the MWIR and LWIR regions where the relevant features for mineral identification are present. The absorption at $10.00 \mu \mathrm{m}$ $\left(1000 \mathrm{~cm}^{-1}\right)$ was common to all samples. Thus, the preliminary mineral identification was based on other smaller yet detectable features. In general, the perlite samples were characterised as mineral mixtures containing mainly opal (feature at $12.5 \mu \mathrm{m}$ or $800 \mathrm{~cm}^{-1}$ ) and montmorillonite (features at 2.6-3.0, 9.0, 10.9 and $11.9 \mu \mathrm{m}$ or 3846 to $3333,1111,917$ and $840 \mathrm{~cm}^{-1}$ ), and minor amount of quartz (feature at $14.3 \mu \mathrm{m}$ or $699 \mathrm{~cm}^{-1}$ ) as main components. Minerals of the zeolite group, usually associated with perlite, were not detected. Complementary XRD analysis suggested the presence of small amounts of plagioclase and discarded other clay minerals. The plagioclase was not detected in the ATR spectra since the dominant absorptions of opal and montmorillonite overlap its spectral features.

From the infrared spectra in Fig. 2 it is evident that the abundance of the containing minerals in perlite ore varies among samples. For an unambiguous determination of the prevalence of one or the other mineral, it was necessary to establish spectral parameters that make a distinction of opal from montmorillonite. Figure 2 shows that the $10.0 \mu \mathrm{m}$ absorption is narrower in the montmorillonite-like spectrum, and therefore it is expected that the overall area of the absorption band is smaller than the one in the opal-like spectrum. Moreover, the inset figure highlights an apparent shift in the wavelength position of the deepest point of the absorption. According to Milkey (1960), this shift is caused by changes in the $\mathrm{Al}: \mathrm{Si}$ ratio, in a way that the deepest point of the band moves towards larger wavelengths as $\mathrm{Al}$ increases. In this context, it would imply an increment in the montmorillonite content.

Based on these observations, the spectral parameters for opal montmorillonite differentiation were defined as the area and the wavelength of the minimum point of the $10.0 \mu \mathrm{m}$ spectral feature. The parameters were computed using built-in functions in The Spectral Geologist software (CSIRO 2007) in continuum removed spectra. The area parameter was calculated as the relative area of the absorption bounded by the maximum reflectance between 7.69 and $11.9 \mu \mathrm{m}\left(840-1300 \mathrm{~cm}^{-1}\right)$. The wavelength of the minimum parameter was calculated as the parabolic interpolation of the wavelength at the lowest point of the absorption in the same given range, using a fit of 7 channels. Table 2 presents the calculated values.

In order to confirm that the observed spectral changes were due to the presence of montmorillonite, the spectral parameters were compared with the major elements composition (Table 2). From these data, Pearson's productmoment correlation coefficients were computed, the results indicated that $\mathrm{Al}_{2} \mathrm{O}_{3}, \mathrm{MgO}$ and $\mathrm{CaO}$ correlated strongly with the area parameter $\left(r_{\mathrm{Al}}=-0.88, r_{\mathrm{Mg}}=-0.92\right.$ and $r_{\mathrm{Ca}}=-0.87$ ); whereas the correlations with wavelength of minimum were smaller $\left(r_{\mathrm{Al}}=0.77, \quad r_{\mathrm{Mg}}=0.75\right.$ and $\left.r_{\mathrm{Ca}}=0.73\right)$, but the trend remained. Figure 3 shows the correlation between the spectral parameters and $\mathrm{Al}_{2} \mathrm{O}_{3}$ and
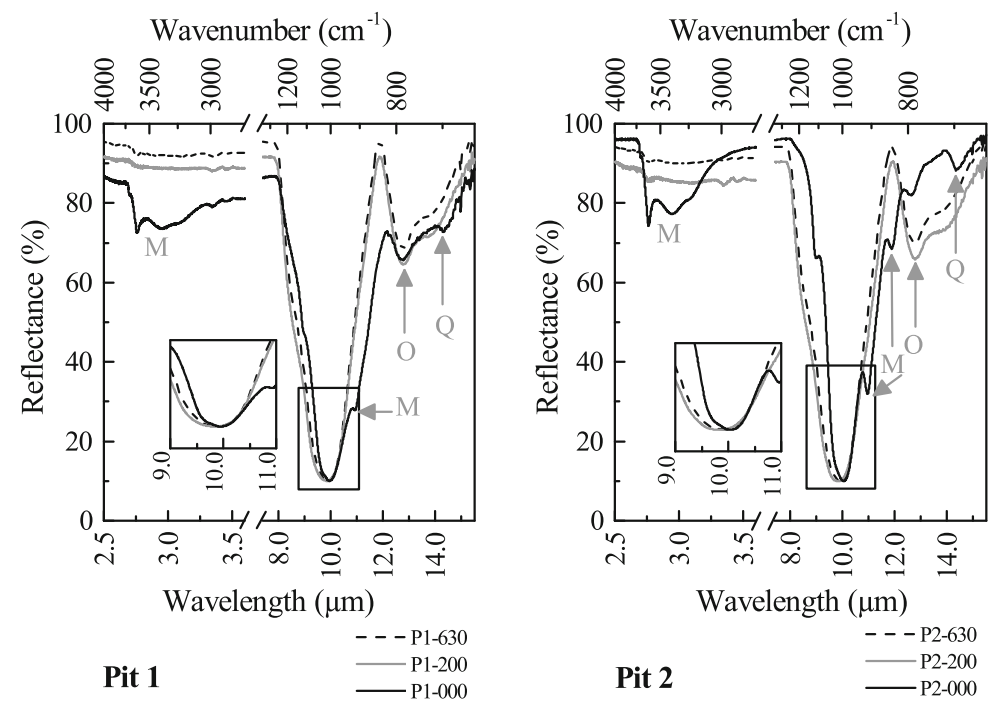

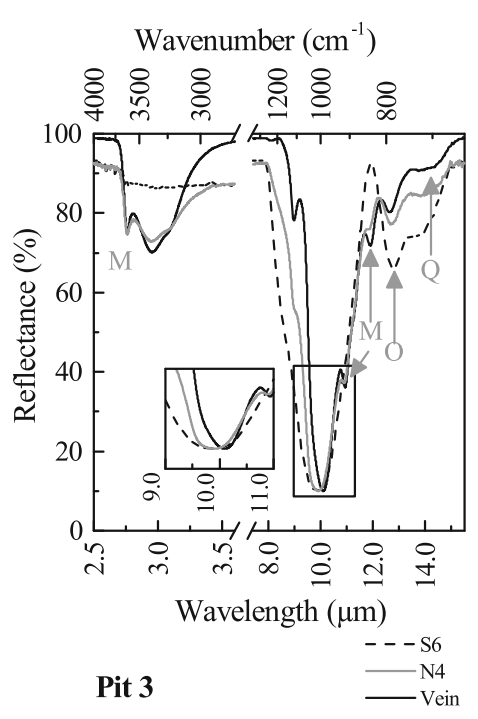

Fig. 2 ATR (MWIR and LWIR) spectra of the perlite samples that represent the mineralogical variability of the ore. The identification of minerals is based on the absorptions at $2.6-3.0 \mu \mathrm{m}$,
9.0, 10.9 and $11.9 \mu \mathrm{m}$ for montmorillonite $(\mathrm{M}), 12.5 \mu \mathrm{m}$ for opal (O) and $14.3 \mu \mathrm{m}$ for quartz (Q). The inset enlarges the shape and wavelength position differences in the $10.0 \mu \mathrm{m}$ absorption 
Table 2 Calculated spectral parameter values and major element chemistry (XRF) of the perlite samples

\begin{tabular}{|c|c|c|c|c|c|c|c|}
\hline \multirow[t]{2}{*}{ Sample ID } & \multicolumn{2}{|c|}{ Spectral parameters } & \multicolumn{5}{|c|}{ Major elements composition } \\
\hline & $\begin{array}{l}\text { Area } \\
(\mathrm{m})\end{array}$ & Wavelength $^{\mathrm{a}}$ & $\begin{array}{l}\mathrm{Al}_{2} \mathrm{O}_{3} \\
(\mathrm{wt} \%)\end{array}$ & $\begin{array}{l}\mathrm{CaO} \\
(\mathrm{wt} \%)\end{array}$ & $\begin{array}{l}\mathrm{MgO} \\
\text { (wt } \%)\end{array}$ & $\begin{array}{l}\mathrm{Na}_{2} \mathrm{O} \\
(\mathrm{wt} \%)\end{array}$ & $\begin{array}{l}\mathrm{SiO}_{2} \\
(\mathrm{wt} \%)\end{array}$ \\
\hline P1-630 & 98.6 & 9.89 & 14.1 & 0.84 & 0.39 & 3.95 & 74.8 \\
\hline P1-400 & 101.35 & 9.88 & 12.4 & 0.91 & 0.24 & 3.20 & 77.0 \\
\hline P1-200 & 101.08 & 9.87 & 13.7 & 0.76 & 0.28 & 4.08 & 76.0 \\
\hline P1-118 & 102.01 & 9.91 & 13.1 & 0.75 & 0.25 & 4.02 & 76.7 \\
\hline P1-060 & 103.29 & 9.89 & 13.1 & 0.74 & 0.24 & 4.01 & 77.0 \\
\hline P1-043 & 98.22 & 9.94 & 13.1 & 0.72 & 0.25 & 3.95 & 76.6 \\
\hline P1-021 & 98.99 & 9.93 & 13.4 & 0.76 & 0.35 & 3.71 & 76.5 \\
\hline P1-013 & 96.48 & 9.95 & 14.5 & 0.91 & 0.46 & 3.55 & 74.3 \\
\hline P1-006 & 96.12 & 9.94 & 14.5 & 1.00 & 0.62 & 3.10 & 74.4 \\
\hline P1-000 & 94.47 & 9.94 & 15.4 & 1.37 & 1.38 & 1.77 & 74.4 \\
\hline P2-630 & 96.73 & 9.92 & 13.9 & 0.83 & 0.56 & 3.48 & 75.9 \\
\hline P2-400 & 98.39 & 9.93 & 13.8 & 0.85 & 0.62 & 3.34 & 76.2 \\
\hline P2-200 & 101.42 & 9.81 & 13.7 & 0.79 & 0.57 & 3.52 & 76.1 \\
\hline P2-118 & 98.19 & 9.85 & 13.4 & 0.83 & 0.53 & 3.49 & 76.7 \\
\hline P2-060 & 99.08 & 9.88 & 13.7 & 0.97 & 0.62 & 3.53 & 75.9 \\
\hline P2-043 & 97.08 & 9.92 & 13.8 & 0.84 & 0.62 & 3.77 & 75.7 \\
\hline P2-021 & 96.28 & 9.94 & 14.3 & 0.92 & 0.87 & 3.33 & 75.4 \\
\hline P2-013 & 90.33 & 10.01 & 16.5 & 1.25 & 1.54 & 2.89 & 72.3 \\
\hline P2-006 & 88.19 & 9.99 & 16.9 & 1.54 & 2.27 & 2.14 & 71.8 \\
\hline P2-000 & 79.22 & 10.05 & 19.4 & 2.32 & 3.79 & 0.76 & 70.1 \\
\hline S8 & 79.56 & 10.09 & 13.6 & 1.25 & 0.79 & 2.19 & 75.2 \\
\hline S7 & 97.37 & 9.86 & 13.5 & 1.17 & 0.79 & 2.28 & 75.9 \\
\hline S6 & 76.87 & 10.02 & 13.2 & 1.07 & 0.54 & 2.61 & 76.2 \\
\hline S5 & 76.67 & 9.99 & 14.3 & 1.29 & 1.44 & 1.91 & 74.9 \\
\hline S4 & 86.80 & 9.96 & 15.3 & 1.55 & 2.14 & 1.49 & 73.7 \\
\hline S3 & 90.82 & 9.89 & 14.3 & 1.22 & 1.34 & 1.95 & 75.1 \\
\hline $\mathrm{S} 2$ & 95.22 & 9.89 & 13.7 & 1.16 & 0.90 & 2.13 & 75.7 \\
\hline $\mathrm{S} 1$ & 104.78 & 9.81 & 15.6 & 1.50 & 2.22 & 1.59 & 73.6 \\
\hline Vein & 101.33 & 9.89 & 16.0 & 5.27 & 2.41 & 0.43 & 63.5 \\
\hline N1 & 103.28 & 9.87 & 18.4 & 2.17 & 3.06 & 0.89 & 70.6 \\
\hline $\mathrm{N} 2$ & 94.56 & 9.86 & 19.1 & 2.59 & 3.42 & 0.72 & 70.1 \\
\hline N3 & 88.93 & 9.90 & 17.1 & 1.76 & 2.21 & 1.41 & 72.6 \\
\hline N4 & 90.60 & 9.90 & 15.6 & 1.70 & 2.17 & 1.41 & 73.4 \\
\hline N5 & 87.32 & 9.92 & 14.2 & 1.19 & 1.16 & 2.00 & 75.2 \\
\hline N6 & 85.22 & 9.90 & 13.6 & 1.03 & 0.71 & 2.46 & 76.0 \\
\hline N7 & 88.91 & 9.90 & 13.7 & 1.02 & 0.57 & 2.70 & 76.0 \\
\hline N8 & 99.73 & 9.91 & 13.6 & 1.02 & 0.53 & 2.74 & 76.3 \\
\hline N9 & 99.14 & 9.90 & 13.9 & 1.08 & 0.81 & 2.40 & 75.8 \\
\hline N10 & 93.24 & 9.90 & 13.6 & 0.99 & 0.56 & 2.67 & 76.2 \\
\hline Mean & 94.25 & 9.91 & 14.6 & 1.28 & 1.10 & 2.60 & 74.6 \\
\hline SD & 7.45 & 0.06 & 1.7 & 0.78 & 0.92 & 1.02 & 2.6 \\
\hline Min & 76.64 & 9.81 & 12.4 & 0.72 & 0.24 & 0.43 & 63.5 \\
\hline Max & 104.78 & 10.09 & 19.4 & 5.27 & 3.79 & 4.08 & 77.0 \\
\hline Error & & & 0.1 & 0.03 & 0.02 & 0.05 & 0.1 \\
\hline
\end{tabular}

${ }^{\mathrm{a}}$ Wavelength of the minimum 

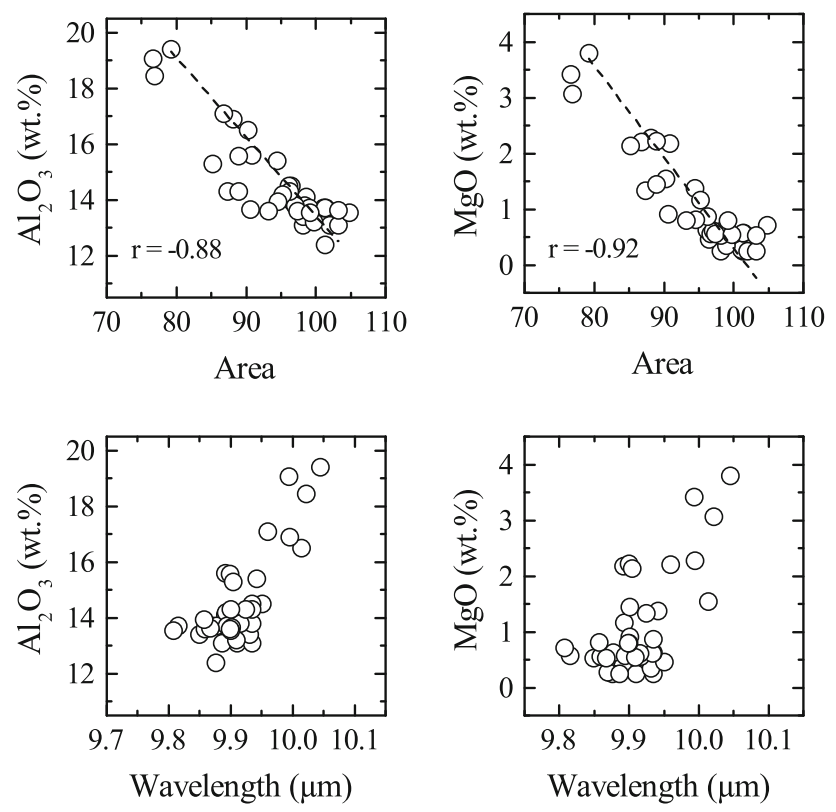

Fig. 3 Correlation between spectral parameters and $\mathrm{Al}_{2} \mathrm{O}_{3}$ and $\mathrm{MgO}$ indicating that small area and long wavelength values indicate the presence of montmorillonite (error bars smaller than plot symbol)

$\mathrm{MgO}$; high concentrations of $\mathrm{Al}_{2} \mathrm{O}_{3}$ and $\mathrm{MgO}$ correspond to spectra with a relatively narrow area and long wavelength, thus confirming that these parameters indicate the presence of montmorillonite. As expected from the correlation coefficients, the area parameter explains better the relationship between spectral and mineralogical changes, whereas for the wavelength of minimum only the high values show a clear correlation pattern.

The variability of the perlite ore was also characterised using SWIR spectroscopy. This technique was chosen for two reasons. Firstly, the results of the ATR analysis identified opal and montmorillonite as the primary constituents in the samples; these two minerals are clearly detectable by using SWIR spectroscopy. Secondly, the final aim of this research is to develop an on-site method for characterising the perlite ore. The availability of portable SWIR spectrometers is appropriate for that purpose.

In the SWIR range, the main features of opal and montmorillonite share the same wavelength position, as Fig. 4 shows, in a similar way as in the MWIR and LWIR ranges. However, significant differences in the shape of the spectra are due to the low crystallinity of the opal, and the way that both minerals host water in their structure. In order to establish a frame of end-members that define the differences in the spectral signatures of opal and montmorillonite, reference data from minerals deemed as spectrally pure were acquired from the USGS spectral library (Clark et al. 2007). Figure 4 displays the spectral differences of the reference opal and montmorillonite endmembers. Three main absorptions at

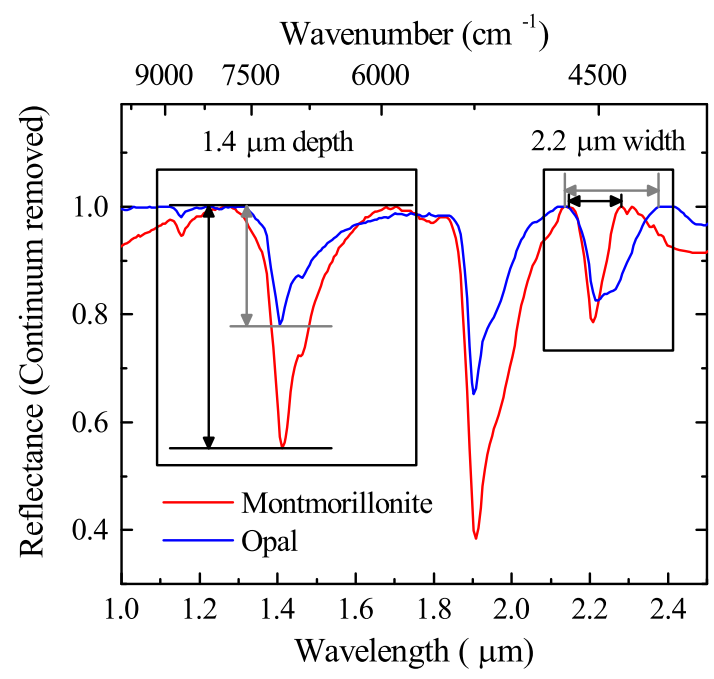

Fig. 4 Reference SWIR spectra of opal and montmorillonite from the USGS spectral library (samples Opal TM8896 and Montmorillonite CM20). Variations in the absorptions at 1.40 and $2.22 \mu \mathrm{m}\left(7143\right.$ and $\left.4505 \mathrm{~cm}^{-1}\right)$ permit to make a distinction between the two end-members

$1.40,1.90$ and $2.22 \mu \mathrm{m} \quad\left(7143,5263\right.$ and $\left.4505 \mathrm{~cm}^{-1}\right)$ describe the variability of the spectra. The $1.40 \mu \mathrm{m}$ $\left(7143 \mathrm{~cm}^{-1}\right)$ feature is related to chemi-adsorbed water, which typically presents a deeper feature in montmorillonite than in opal, due to stronger bonding. The $2.22 \mu \mathrm{m}$ $\left(4505 \mathrm{~cm}^{-1}\right)$ absorption is related to hydroxyl-metal bonds, which are $\mathrm{Si}-\mathrm{OH}$ for opal and $\mathrm{Al}-\mathrm{OH}$ for montmorillonite; this variation in composition results in a spectral band wide and asymmetrical for opal, and a narrow and symmetric for montmorillonite. The absorption at $1.90 \mu \mathrm{m}\left(5263 \mathrm{~cm}^{-1}\right)$ corresponds to molecular water (Hunt 1977).

The combination of the spectral absorptions can be used to discriminate between the dominant mineralogy in the perlite ore. The narrowing of the $2.22 \mu \mathrm{m}\left(4505 \mathrm{~cm}^{-1}\right)$ and the deepening of the $1.40 \mu \mathrm{m}\left(7143 \mathrm{~cm}^{-1}\right)$ features indicate the enrichment from opal to montmorillonite. To visualise this transition, the Opal-Montmorillonite (OM) Index was defined, as follows:

OM Index $=2.2 w / 1.4 d$

where $2.2 w$ is the width at $2.22 \mu \mathrm{m}$, measured as the distance between the shoulders of the absorption, and $1.4 d$ is the depth at $1.40 \mu \mathrm{m}$. These parameters were calculated using built-in functions in The Spectral Geologist software (CSIRO 2007), with the reflectance spectrum in micrometres and continuum removed. Calculation of the $\mathrm{OM}$ index for the reference samples gave $\mathrm{OM}$ values of 0.97 for opal and 0.21 for montmorillonite.

The calculated $\mathrm{OM}$ index values for the perlite ore samples are presented in Table 3. Extreme OM values 
Table 3 Calculated OM index values for the particle size fractions samples (Pit 1 and 2) and for the alteration profile samples (Pit 3)
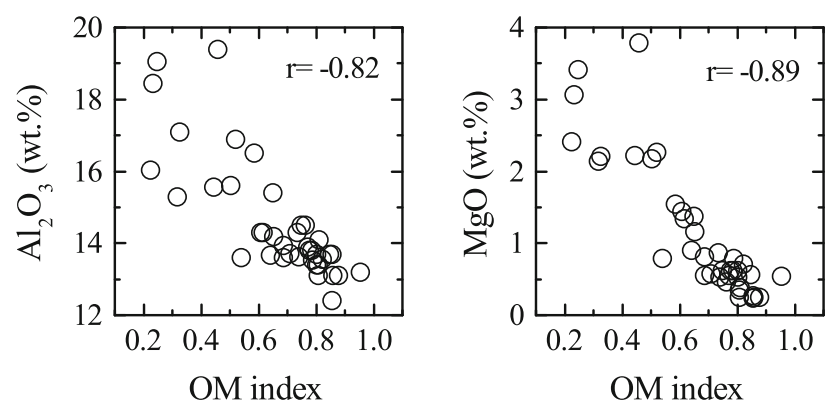

Fig. 5 Correlation between the $\mathrm{OM}$ index and $\mathrm{Al}_{2} \mathrm{O}_{3}$ and $\mathrm{MgO}$ content that confirms the presence of montmorillonite at low $\mathrm{OM}$ values. (Error bars smaller than plot symbol)

indicate the presence of almost pure end-members. Major element chemistry validated the robustness of the index. In Fig. 5, the OM index is compared to the $\mathrm{Al}_{2} \mathrm{O}_{3}$ and $\mathrm{MgO}$ content, showing that in general there is an inverse correspondence between the spectral index and the $\mathrm{Al}$ and $\mathrm{Mg}$ enrichment, which confirms the presence of montmorillonite at low OM values.

In Pit 3, the changes in texture and colour of the pit face expose the rhyolite intrusion, as shown in Fig. 1. However, it was difficult to assess the impact of the alteration in the surrounding ore without the use of more sophisticated techniques. In this case, the OM index aided in the characterisation of the mineralogical variation associated with the intrusion. As seen in Table 3, the lowest $\mathrm{OM}$ values are from the samples located in the vicinity of the vein, and they increase with increasing distance from the intrusion. The variations in the OM index mean that in the zone of intense hydrothermal influence, the ore is strongly altered to montmorillonite. With increasing distance from the intrusion, the perlite ore is gradually less disturbed, and therefore the mineralogy becomes dominated by opal. Even though these considerations might be self-evident in an epithermal alteration setting, on-site observations (i.e. colour or textural differences) only permit distinction of the area next to the rhyolitic vein. The detection of a gradual transition from the altered area to unaltered perlite ore can be only evident by means of more sophisticated techniques, even more in scenarios where the alteration is not uniform in all directions. In this context, the $\mathrm{OM}$ index is important since it enables the establishment of spatial trends and the dimensions of the altered zone, which are not visually apparent in the pit. 
In Pits 1 and 2, the size fraction samples present the same mineralogical variability as the samples from Pit 3. The calculated OM index for Pits 1 and 2, presented in Table 3, reproduces the observations made previously for the MWIR and LWIR spectra (Fig. 7). The OM values for Pit 1 vary between 0.65 and 0.88 , reflecting a limited mineralogical variation in the samples, which is opaldominant. In contrast, the OM values for Pit 2 fluctuate in a broader range indicating that the mineralogical variability includes both opal and montmorillonite dominance.

\section{Particle size analysis}

The cumulative and range particle size distribution (PSD) curves of Pits 1 and 2 are displayed in Fig. 6. The cumulative PSD curves show in general a similar pattern for both pits, with a good representation of all the size fractions thus indicating a well-graded material. However, subtle yet relevant differences were detected, particularly in the small size fraction up to $0.60 \mathrm{~mm}$. In this range, the volume of particles was larger in Pit 2 than in Pit 1, with the greatest contribution at the $0.21 \mathrm{~mm}$ fraction; this trend changed at $0.60 \mathrm{~mm}$ where Pit 1 produced a larger volume of particles than Pit 2, as the range PSD curve shows. The differences in small size fraction between the two pits are relevant for the determination of the source of fine particles, as is

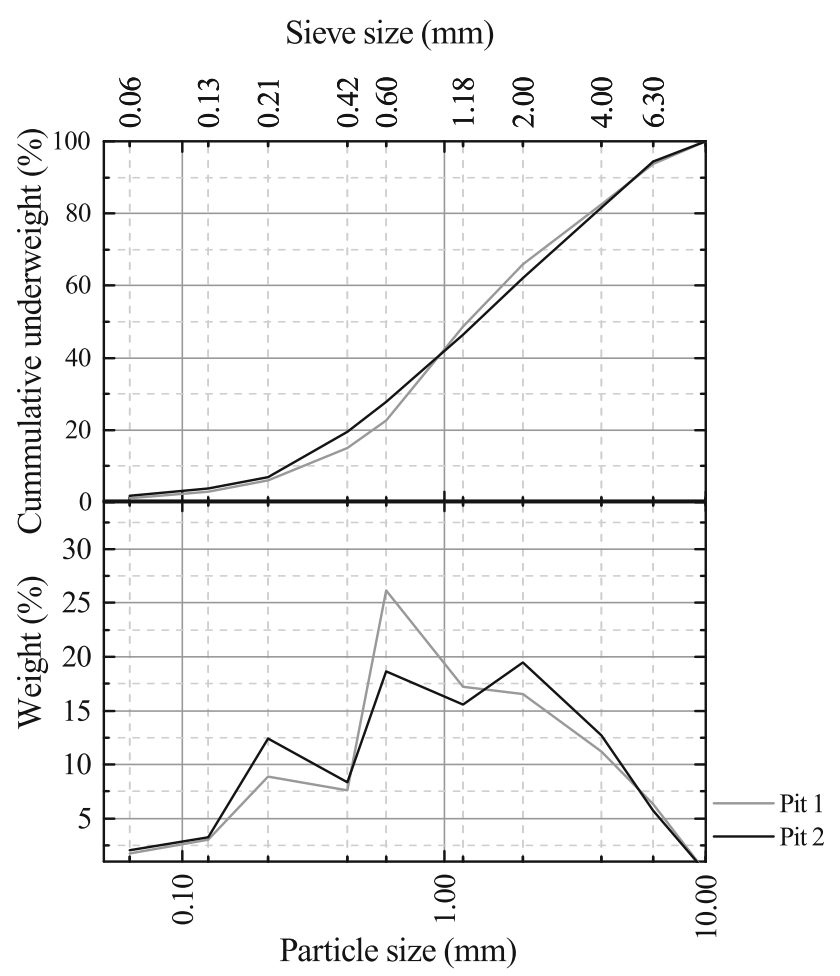

Fig. 6 Particle size distribution curves of Pits 1 and 2: cumulative distribution (top) and range distribution (bottom) further discussed in "Ore variability as detector of environmental risks" section.

Figure 2 made evident the variation in mineralogy related to the particle size. The coarse and medium fractions (samples P1-630, P1-200, P2-630 and P2-200) have only spectral features characteristic of opal, whereas in the fine fraction (samples P1-000 and P2-000) the spectral absorptions of montmorillonite prevail. It is also noticeable that the variations in mineralogy differed in Pits 1 and 2, particularly for the fine fraction.

Based on those observations, Fig. 7 shows a comparison of the spectral parameters, presented previously in Table 2, and the particle size fractions. In order to facilitate the interpretation, arbitrary thresholds were established to determine the dominance of opal, montmorillonite or a mixture. The thresholds were not only based on the spectral parameters but also on the secondary features and the correlation coefficients. There are remarkable differences between Pit 1 and 2. In general, Pit 1 presents less spectral variation than Pit 2, indicating a more homogeneous mineralogy. A closer inspection of the size fractions shows that in Pit 2, montmorillonite is dominant at the smaller particles, from $>0.06$ to $0.13 \mathrm{~mm}$, whereas in Pit 1 this is the case only for the finest fraction. In contrast, indicators of opal dominance are more frequent in Pit 1 , from 0.60 to $4.00 \mathrm{~mm}$, whereas in Pit 2 opal is only clearly dominant at $2.00 \mathrm{~mm}$.

An integrated analysis of the particle size distribution (Fig. 6) and the mineralogical variations permit the understanding of their relationship. The perlite ore is essentially a mineral mixture of opal and montmorillonite. The grinding and sieving rapidly liberate the montmorillonite, which due to its physical properties turns into the main constituent of the small size fraction. Because of this, in the medium size fraction the montmorillonite content is minimised, and therefore the ore is richer in opal. As indicated by the mineral content of the coarsest size fractions, the raw ore of Pit 2 has more montmorillonite than that of Pit 1; therefore, it has a higher potential of producing small particles. Moreover, in Pit 2 remains of montmorillonite along the entire size distribution hinder the production of other size fractions consistently dominant in opal. In contrast, the reduced proportion of montmorillonite in the raw ore of Pit 1 limits the generation of large volumes of fine particles. Furthermore, it favours the production of particles with a nearly opal-dominant mineralogy in a broader size fraction range. These observations have direct implications for mineral processing and quality control, as it will be further discussed.

\section{Chemical impurities}

The rhyolite intrusion in Pit 3 poses favourable conditions for the analysis of impurities in the perlite ore. The samples 
Fig. 7 Comparison of spectral parameters and the particle size fractions. Broad area and short wavelength indicate that opal $(\mathrm{O})$ is dominant, whereas narrow area and long wavelength indicate dominance in montmorillonite $(\mathrm{M})$. Intermediate features are deemed as mixtures (m). The thresholds are arbitrary

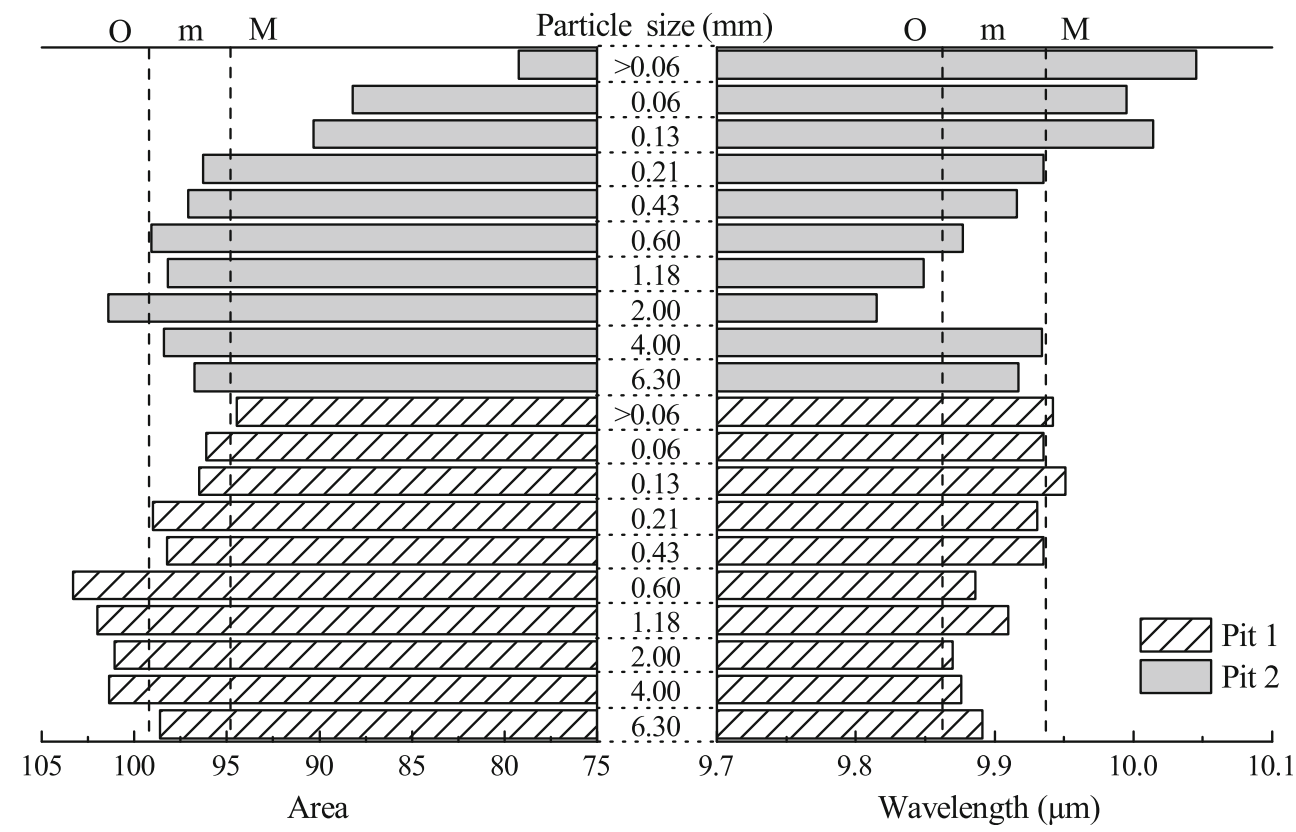

coming from this pit were expected to have a higher content of chemical impurities compared to the rest of the perlite deposit, and therefore they were used as a pilot test to assess their relationship with the ore. Table 4 provides the concentration of the chemical impurities detected by XRF. The interpretation of high or low concentration values of a given analyte was based on the standards reported in Table 1. It is apparent from Table 4 that the Fe concentration is remarkably high along the sample set; the $\mathrm{Nd}, \mathrm{Pb}$ and $\mathrm{Sb}$ concentrations are slightly over the accepted threshold; As, Co and $\mathrm{Hg}$ are within the acceptance criteria, and $\mathrm{Cr}$ and $\mathrm{Ni}$ have very low levels. Moreover, from the overall list of chemical impurities $\mathrm{Cd}, \mathrm{F}$ and Se are not reported. The concentration values are higher at the hydrothermal vein for most of the elements, except for $\mathrm{As}, \mathrm{Ba}$ and $\mathrm{Rb}$, for which the vein has the lowest concentration values, and for $\mathrm{Cr}, \mathrm{Hg}$ and $\mathrm{Pb}$, for which no striking values are noted.

A preliminary analysis using Pearson's product-moment correlation coefficients highlighted the expected elemental associations between As- $\mathrm{Ba}(r=0.89)$, As- $\mathrm{Rb}(r=0.93)$ and $\mathrm{Ba}-\mathrm{Rb}(r=0.89)$ on the one hand, and between $\mathrm{Fe}-\mathrm{Ti}$ $(r=0.86), \mathrm{Fe}-\mathrm{Zn}(r=0.94)$ and $\mathrm{Ti}-\mathrm{Zn}(r=0.77)$ on the other hand. Principal Component Analysis (PCA) was carried out to understand the nature of such associations in the perlite pit and to elucidate any other possible correlations. From the elements reported in Table 4, Co, Cr and $\mathrm{Ni}$ were excluded from the analysis due to the frequent presence of values below the XRF detection limit; the vein sample was also excluded since its extreme values represent an anomaly in the data set.

The loadings of the first and second principal components are displayed in Fig. 8a, b presents the geochemical transects of the elements with the higher loadings to support the PCA interpretation. PC1 depicts the correlations already described by the Pearsons correlation. Specifically, it establishes a negative correlation between the elements that have a higher concentration at the rhyolite vein (represented by negative loadings), from those which concentrations are lower at that location (represented by positive loadings). There are thus apparent opposite spatial trends for the concentration of $\mathrm{As}-\mathrm{Ba}-\mathrm{Rb}$ and $\mathrm{Fe}-\mathrm{Ti}-\mathrm{Zn}$. Moreover, the geochemical transect shows that $\mathrm{Fe}-\mathrm{Ti}-\mathrm{Zn}$ are constrained to the central part of the system, whereas As$\mathrm{Ba}-\mathrm{Rb}$ have increased values in the peripheral areas. For the elements with positive loadings in PC2, the values at the vein are the highest; even though there are spiky values in the rest of the transect, as the Nd plot shows (Fig. 8b), they lack any spatial trend and do not seem to have a correlation with a specific sample location. The spatial distribution of $\mathrm{Hg}, \mathrm{Pb}$ and $\mathrm{Sb}$ does not seem to be related to the rhyolitic intrusion since neither striking values nor spatial trends are detected.

The alteration in Pit 3 involves displacement of $\mathrm{Si}$, which leads to $\mathrm{Al}$ enrichment next to the intrusion with the subsequent formation of montmorillonite. Following the methodology used by Christidis (1998), the metals regarded as chemical impurities were compared with the $\mathrm{Al}_{2} \mathrm{O}_{3}$ content to assess the element mobility during the alteration caused by the hydrothermal intrusion. The sample regarded as opal-dominant according to the OM ("Mineralogical variability of the perlite ore" section) index was used as a reference for relative enrichment towards the Si phase. In Fig. 9a, Ti has a linear relationship with the regression line passing through the origin, indicating that $\mathrm{Ti}$ is immobile 
Table 4 XRF concentration of the chemical impurities in samples from Pit 3

\begin{tabular}{|c|c|c|c|c|c|c|c|c|c|c|c|c|c|c|c|}
\hline $\begin{array}{l}\text { Sample ID } \\
\text { Threshold }^{\mathrm{a}}\end{array}$ & $\begin{array}{l}\text { Distance } \\
(\mathrm{m})\end{array}$ & $\begin{array}{l}\text { As } \\
\text { ppm } \\
1-12\end{array}$ & $\begin{array}{l}\text { Ba } \\
\text { ppm } \\
\text { Report }\end{array}$ & $\begin{array}{l}\text { Co } \\
\text { ppm } \\
1\end{array}$ & $\begin{array}{l}\mathrm{Cr} \\
\mathrm{ppm} \\
5\end{array}$ & $\begin{array}{l}\mathrm{Cu} \\
\text { ppm } \\
\text { Report }\end{array}$ & $\begin{array}{l}\mathrm{Fe} \\
\mathrm{ppm} \\
300\end{array}$ & $\begin{array}{l}\mathrm{Hg} \\
\text { ppm } \\
0.1-1.0\end{array}$ & $\begin{array}{l}\mathrm{Nd} \\
\mathrm{ppm} \\
20\end{array}$ & $\begin{array}{l}\mathrm{Ni} \\
\mathrm{ppm} \\
10\end{array}$ & $\begin{array}{l}\mathrm{Pb} \\
\mathrm{ppm} \\
5-30\end{array}$ & $\begin{array}{l}\text { Rb } \\
\text { ppm } \\
\text { Report }\end{array}$ & $\begin{array}{l}\mathrm{Sb} \\
\mathrm{ppm} \\
2\end{array}$ & $\begin{array}{l}\mathrm{Ti} \\
\text { ppm } \\
\text { Report }\end{array}$ & $\begin{array}{l}\mathrm{Zn} \\
\text { ppm } \\
\text { Report }\end{array}$ \\
\hline S8 & -8.0 & 9 & 1350 & $<1$ & 2 & 2 & 5204 & 0.05 & 23 & $<1$ & 36 & 130 & 6 & 671 & 37 \\
\hline S7 & -7.0 & 8 & 1338 & 1 & 2 & 1 & 5567 & 0.05 & 17 & $<1$ & 35 & 123 & 4 & 665 & 34 \\
\hline S6 & -6.0 & 9 & 1359 & $<1$ & $<1$ & 2 & 4581 & 0.04 & 25 & $<1$ & 51 & 122 & 5 & 689 & 32 \\
\hline S5 & -5.0 & 7 & 1236 & $<1$ & 1 & 2 & 4973 & 0.03 & 21 & $<1$ & 36 & 121 & 5 & 701 & 37 \\
\hline S4 & -4.0 & 7 & 1116 & 2 & 1 & 2 & 6057 & 0.02 & 23 & 1 & 40 & 114 & 4 & 737 & 39 \\
\hline S3 & -3.0 & 9 & 1242 & 1 & 1 & 2 & 4539 & 0.05 & 25 & $<1$ & 36 & 121 & 5 & 671 & 35 \\
\hline S2 & -2.0 & 9 & 1324 & 1 & $<1$ & 2 & 4812 & 0.03 & 23 & $<1$ & 58 & 124 & 4 & 677 & 34 \\
\hline S1 & -1.0 & 7 & 1073 & 1 & 1 & 2 & 6169 & 0.14 & 25 & $<1$ & 37 & 110 & 5 & 761 & 42 \\
\hline Vein & 0.0 & 2 & 757 & 3 & 1 & 4 & 11,086 & 0.10 & 33 & 2 & 42 & 16 & 6 & 935 & 69 \\
\hline N1 & 1.0 & 5 & 750 & 1 & 2 & 1 & 9009 & 0.06 & 20 & 1 & 42 & 77 & 5 & 899 & 47 \\
\hline $\mathrm{N} 2$ & 2.0 & 5 & 618 & 1 & 1 & 1 & 6819 & 0.03 & 21 & 1 & 44 & 60 & 6 & 953 & 41 \\
\hline N3 & 3.0 & 6 & 1004 & 1 & 2 & 3 & 6917 & 0.07 & 24 & 1 & 37 & 89 & 5 & 839 & 39 \\
\hline N4 & 4.0 & 7 & 1191 & $<1$ & 1 & 2 & 5868 & 0.07 & 19 & $<1$ & 36 & 109 & 5 & 743 & 37 \\
\hline N5 & 5.0 & 8 & 1266 & 1 & 1 & 2 & 5658 & 0.03 & 30 & $<1$ & 40 & 125 & 6 & 773 & 41 \\
\hline N6 & 6.0 & 10 & 1336 & 2 & 3 & 1 & 5428 & 0.06 & 21 & $<1$ & 37 & 124 & 6 & 671 & 36 \\
\hline N7 & 7.0 & 9 & 1339 & 1 & $<1$ & 2 & 4903 & 0.06 & 24 & $<1$ & 36 & 123 & 6 & 671 & 33 \\
\hline N8 & 8.0 & 8 & 1342 & $<1$ & 2 & 2 & 4784 & 0.02 & 22 & $<1$ & 35 & 121 & 5 & 647 & 32 \\
\hline N9 & 9.0 & 9 & 1355 & 1 & $<1$ & 2 & 5050 & 0.05 & 27 & $<1$ & 36 & 123 & 4 & 671 & 34 \\
\hline N10 & 10.0 & 9 & 1357 & $<1$ & $<1$ & 2 & 4707 & 0.03 & 21 & $<1$ & 34 & 124 & 5 & 653 & 32 \\
\hline Mean & & 7.5 & 1176.5 & 1.3 & 1.5 & 1.9 & 5901.6 & 0.05 & 23.4 & 0.32 & 39.4 & 108.2 & 5.1 & 738.3 & 38.5 \\
\hline $\mathrm{SD}$ & & 1.95 & 233.92 & 0.63 & 0.65 & 0.7 & 1627.2 & 0.03 & 3.76 & 0.58 & 6.1 & 28.91 & 0.74 & 98.23 & 8.4 \\
\hline Min & & 2 & 618 & $<1$ & $<1$ & 1 & 4539 & 0.02 & 17 & 0 & 34 & 16 & 4 & 647 & 32 \\
\hline Max & & 10 & 1359 & 3 & 3 & 4 & 11,086 & 0.14 & 33 & 2 & 58 & 130 & 6 & 953 & 69 \\
\hline Error & & 1 & 70 & 1 & 1 & 1 & 230 & 0.01 & 5 & 1 & 10 & 15 & 1 & 60 & 15 \\
\hline
\end{tabular}

The values of the rhyolitic vein samples are in bold. All the values initially reported as oxides were converted into ppm to facilitate comparison with the standards

${ }^{a}$ Threshold values for chemical impurities as specified in Table 1

Fig. 8 a Loadings of the first and second principal components of the chemical impurities in perlite at Pit 3 to establish correlations among elements; b geochemical transects in relation to the position of the rhyolitic vein of the elements with meaningful correlations and higher PC1 and PC2 loadings (a)

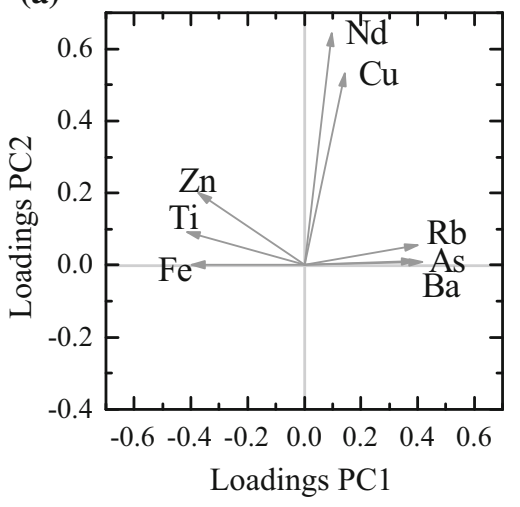

(b)

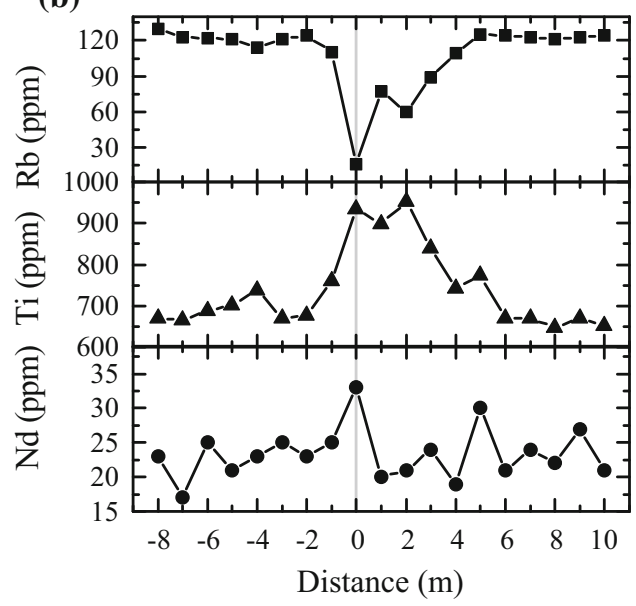

and is enriched in the montmorillonite by residual behaviour. $\mathrm{Zn}$ and $\mathrm{Fe}$ also have a positive linear correlation (Fig. 9b, c), but the shift in the intersection of the regression line in respect of the origin means that the alteration fluid phase introduced these elements. In the $\mathrm{Rb}, \mathrm{Ba}$ and $\mathrm{As}$ plots (Fig. 9d-f) the samples lie below the origin-to-opal line, and the regression line has a negative slope indicating leaching of these elements along with the Si phase, leading 

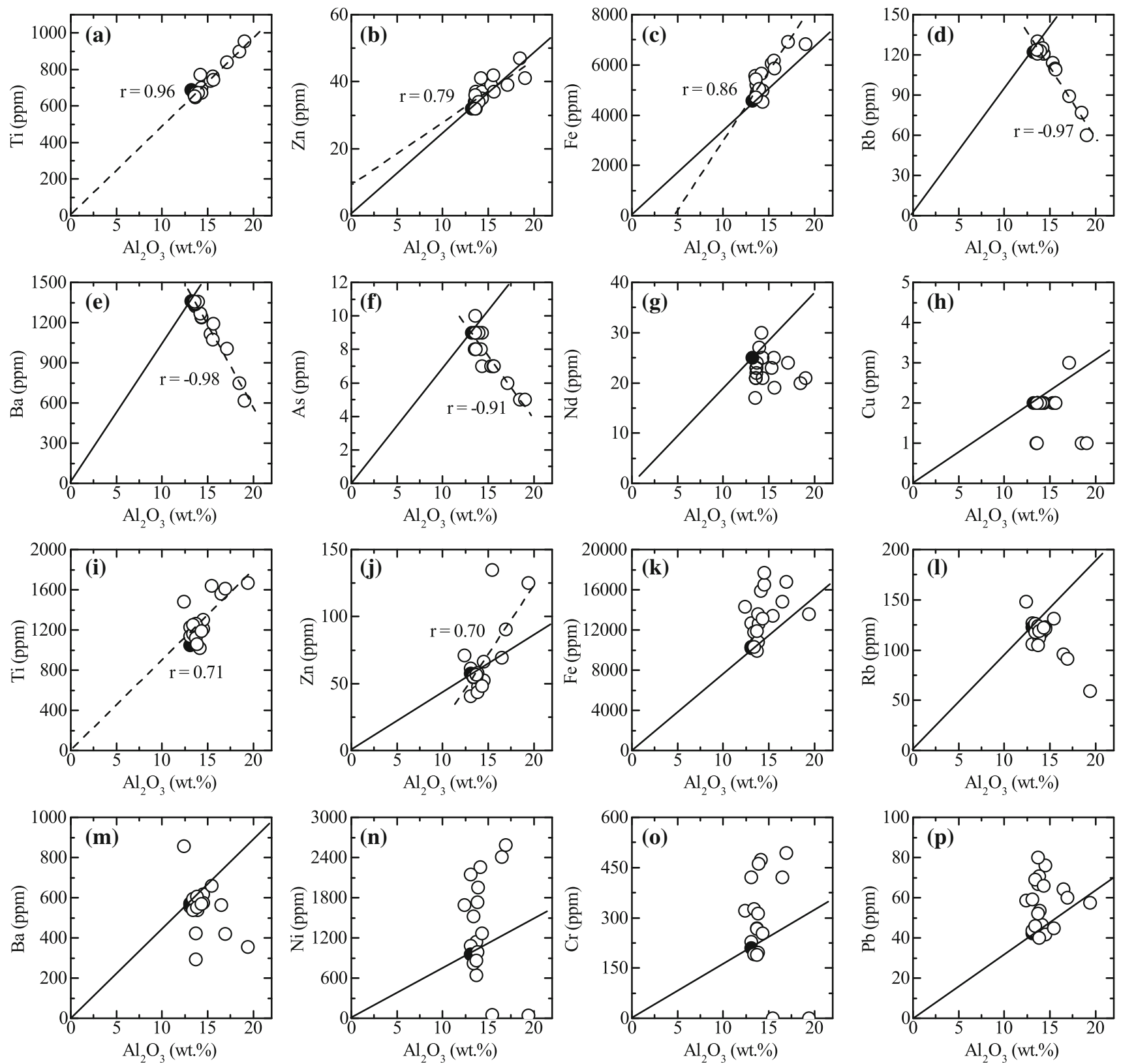

Fig. 9 Projection of perlite's chemical impurities (ppm) over $\mathrm{Al}_{2} \mathrm{O}_{3}$ (wt $\%$ ) to assess their relative mobility due to hydrothermal alteration in Pit $3(\mathbf{a}-\mathbf{h})$, and due to perlite formation or groundwater percolation in Pits 1 and $2(\mathbf{i}-\mathbf{p})$. The solid circle is the most opal-dominant

to their enrichment in the opal-dominant ore. Lack of patterns and scattering in the $\mathrm{Nd}$ and $\mathrm{Cu}$ plots (Fig. 9g, h) suggest that their mobility is not related to residual behaviour.

The chemical impurities of the size fractions samples are displayed in Table 5. There are a number of significant differences between the size fractions samples (Pits 1 and 2) and the hydrothermally influenced samples (Pit 3). First, As, $\mathrm{Co}, \mathrm{Hg}$ and $\mathrm{Sb}$ are not reported for Pits 1 and 2; the values for these elements were very low already in Pit 3 ,

sample according to the OM index, the full lines is the origin-to-opal line as a reference for relative enrichment, and the dashed line is linear regression

and it is possible that they are not present, or their concentrations are below the XRF detection limit. Second, $\mathrm{Cu}$ and $\mathrm{Nd}$ are only present at certain size fractions. Interestingly, the reported levels of these two elements along with those of $\mathrm{Cr}$ and $\mathrm{Ni}$ are remarkably higher than in Pit 3 .

The relationships in the chemical impurities for Pits 1 and 2 were analysed following the same PCA approach as for Pit 3; $\mathrm{Cu}$ and $\mathrm{Nd}$ were excluded from the analysis due to the missing values. The loadings of $\mathrm{PC} 1$ and $\mathrm{PC} 2$, shown in Fig. 10a, present similarities with the Pit 3 analysis 
Table 5 XRF concentration of chemical impurities in samples from the size fractions of samples from Pits 1 and 2

\begin{tabular}{|c|c|c|c|c|c|c|c|c|c|c|c|c|c|c|c|}
\hline Threshold ${ }^{\mathrm{a}}$ & $\begin{array}{l}\text { Particle } \\
\text { size } \\
\mathrm{mm}\end{array}$ & $\begin{array}{l}\text { As } \\
\text { ppm } \\
1-12\end{array}$ & $\begin{array}{l}\text { Ba } \\
\text { ppm } \\
\text { Report }\end{array}$ & $\begin{array}{l}\text { Co } \\
\text { ppm }\end{array}$ & ppm & ppm & ppm & $\begin{array}{l}\mathrm{Hg} \\
\text { ppm }\end{array}$ & ppm & ppm & $\begin{array}{l}\mathrm{Pb} \\
\mathrm{ppm}\end{array}$ & $\begin{array}{l}\mathrm{Rb} \\
\text { ppm } \\
\text { Report }\end{array}$ & $\begin{array}{l}\mathrm{Sb} \\
\mathrm{ppm}\end{array}$ & $\begin{array}{l}\text { Ti } \\
\text { ppm }\end{array}$ & $\begin{array}{l}\text { Zn } \\
\text { ppm } \\
\text { Report }\end{array}$ \\
\hline inresnola & & & & & & & & & & & & & & & \\
\hline P1-630 & 6.30 & - & 526 & - & 324 & - & 11,121 & - & - & 1776 & 45 & 108 & - & 612 & 39 \\
\hline P1-400 & 4.00 & - & 766 & - & 220 & - & 10,002 & - & - & 1328 & 57 & 135 & - & 887 & 57 \\
\hline P1-200 & 2.00 & - & 527 & - & 183 & 24 & 7554 & - & - & 896 & 65 & 112 & - & 743 & 45 \\
\hline P1-118 & 1.18 & - & 498 & - & 157 & 547 & 7134 & - & 183 & 849 & 58 & 116 & - & 737 & 49 \\
\hline P1-060 & 0.60 & - & 513 & - & 143 & - & 7204 & - & - & 753 & 41 & 112 & - & 629 & 46 \\
\hline P1-043 & 0.43 & - & 506 & - & 288 & 458 & 8883 & - & - & 1690 & 42 & 97 & - & 683 & 32 \\
\hline P1-021 & 0.21 & - & 531 & - & 223 & - & 8253 & - & - & 1194 & 45 & 115 & - & 695 & 44 \\
\hline P1-013 & 0.13 & - & 552 & - & 450 & 51 & 11,541 & - & 111 & 2986 & 74 & 112 & - & 725 & 42 \\
\hline P1-006 & 0.06 & - & 516 & - & 430 & - & 12,380 & - & - & 2790 & 40 & 111 & - & 779 & 53 \\
\hline P1-000 & $<0.06$ & - & 590 & - & - & - & 9372 & - & - & 37 & 44 & 120 & - & 983 & 108 \\
\hline P2-630 & 6.30 & - & 481 & - & 315 & 38 & 8813 & - & - & 1532 & 52 & 109 & - & 731 & 38 \\
\hline P2-400 & 4.00 & - & 543 & - & 134 & - & 7554 & - & - & 778 & 69 & 102 & - & 719 & 47 \\
\hline P2-200 & 2.00 & - & 261 & - & 183 & 52 & 6924 & - & - & 504 & 78 & 96 & - & 755 & 44 \\
\hline P2-118 & 1.18 & - & 481 & - & 131 & - & 7204 & - & - & 647 & 67 & 108 & - & 749 & 44 \\
\hline P2-060 & 0.60 & - & 379 & - & 130 & - & 8323 & - & - & 678 & 51 & 113 & - & 671 & 46 \\
\hline P2-043 & 0.43 & - & 493 & - & 213 & 555 & 9512 & - & - & 1360 & 39 & 109 & - & 635 & 35 \\
\hline P2-021 & 0.21 & - & 510 & - & 174 & 38 & 9163 & - & 94 & 998 & 64 & 112 & - & 713 & 39 \\
\hline P2-013 & 0.13 & - & 503 & - & 288 & 26 & 10,352 & - & - & 1894 & 63 & 88 & - & 935 & 56 \\
\hline P2-006 & 0.06 & - & 377 & - & 338 & 36 & 11,750 & - & - & 2035 & 58 & 83 & - & 965 & 73 \\
\hline P2-000 & $<0.06$ & - & 318 & - & - & 388 & 9512 & - & - & 34 & 56 & 54 & - & 1001 & 100 \\
\hline Mean & & - & 493.51 & - & 240.19 & 201.32 & 9127.6 & - & 129.46 & 1237.9 & 55.38 & 105.63 & - & 767.67 & 51.87 \\
\hline SD & & - & 104.11 & - & 100.23 & 230.86 & 1664.2 & - & 47.48 & 794.79 & 11.83 & 16.55 & - & 120.4 & 20.07 \\
\hline Min & & - & 261 & - & 130 & 24 & 6924 & - & 94 & 34 & 39 & 54 & - & 612 & 32 \\
\hline Max & & - & 766 & - & 450 & 555 & 12,380 & - & 183 & 2986 & 78 & 135 & - & 1001 & 105 \\
\hline $\begin{array}{l}\text { Absolute } \\
\text { error }\end{array}$ & & - & 68 & - & 38 & 16 & 230 & - & 29 & 15 & 21 & 27 & & 60 & 18 \\
\hline
\end{tabular}

${ }^{a}$ Threshold values for chemical impurities as specified in Table 1

regarding the correlations between $\mathrm{Ti}-\mathrm{Zn}$ and $\mathrm{Rb}-\mathrm{Ba}$. For these four elements, the respective geochemical plots (Fig. 9i, j, 1, m) suggest similar enrichment mechanisms to those in Pit 3, that is to say, in-situ enrichment of Ti and $\mathrm{Zn}$ is due to immobility in respect of $\mathrm{Al}$, and $\mathrm{Rb}$ and $\mathrm{Ba}$ are leached along with $\mathrm{Si}$. In this case, the alteration phase might be related to the perlite genesis, which leads to the formation of montmorillonite and opal, rather than a posterior process. However, all the elements analysed in Pits 1 and 2 (Fig. 9i-p) present more scattering that the geochemical plots of Pit 3; moreover, in the PCA plot it is notorious that $\mathrm{Fe}$ does not correlate anymore with $\mathrm{Ti}$ and $\mathrm{Zn}$, but instead presents more similarities with $\mathrm{Ni}$ and $\mathrm{Cr}$. The increased scattering in the geochemical plots might indicate a possible uptake of metals from an external source, given either by the alteration fluid responsible for the perlitisation or by percolation of groundwater that leached the metals from the surrounding rock units.

A comparison between the chemical impurities and the particle size permitted a first assessment of their relationship. Figure 10b displays plots for $\mathrm{Rb}, \mathrm{Ti}$ and $\mathrm{Ni}$, which represent the most extreme PC loadings and ease the comparability with the results from Pit 3, against the size particle. The elevated concentrations of $\mathrm{Ti}$ and $\mathrm{Ni}$ seem to be associated with the fine particles, except for the smallest size fraction where $\mathrm{Ni}$ is at its lowest. For this element, the rest of the particles show a gradual change from high to low concentrations in the middle size fraction, and again towards relatively high levels in the coarsest particles. However, it is not possible to establish a clear relationship between the variations of the chemical impurities and the size fractions. A probable reason for this is that the analysis ignores the fact that particles of the same size fraction might have different mineralogy, depending on the source of the ore, as indicated in "Particle size analysis" section. Therefore, for explaining the variations of the chemical impurities, it is more appropriate to consider mineralogical variables, as presented in the "Ore variability as detector of environmental risks" section. 
Fig. 10 a Loadings of the first and second principal components of the chemical impurities in perlite at Pits 1 and 2 to establish correlations among elements and differences with Pit 3 ; $\mathbf{b}$ variation in the concentration of $\mathrm{Rb}, \mathrm{Ti}$ and $\mathrm{Ni}$ related to the size fraction. No apparent correlations are found (a)

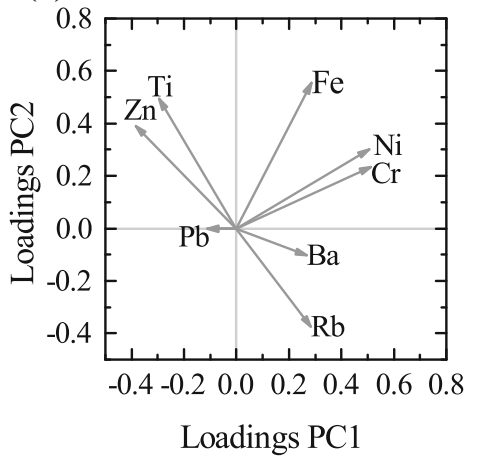

(b)

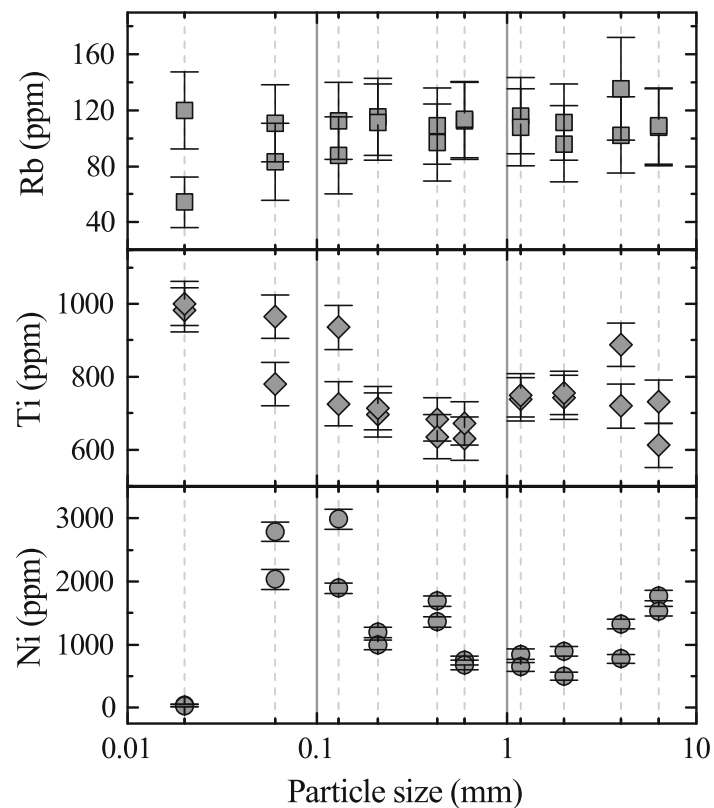

\section{Ore variability as detector of environmental risks}

The particle size analysis indicated that the mineralogical content of the perlite ore could play a major role as a controlling factor for some of the perlite properties. Additionally, the presence of hydrothermal alteration in Pit 3 suggests that changes in the ore mineralogy and the variations in the presence of chemical impurities might be related. Therefore, the OM index calculated in "Mineralogical variability of the perlite ore" section was used to check the validity of those observations.

Integration of the OM index and XRF data suggested a possible correlation between the mineralogical variations in the perlite ore and the chemical impurities. The integration approach included only the PCA results from Pit 3. Figure 11a displays the scores and loadings of the PC1 and PC2; every point represents a sample, and the colouring corresponds to the respective $\mathrm{OM}$ index value. The plot presents the likelihood of a montmorillonite- or opaldominant phase to have elevated concentrations of chemical impurities. The scores in PC1 describe well the variations in mineralogy, where negative scores represent the montmorillonite-dominant samples, and opal-dominant samples are those with positive scores. From the PC loadings, previously described in Fig. 8a, it can be seen that the elevated $\mathrm{Fe}-\mathrm{Ti}-\mathrm{Zn}$ concentrations correspond to the montmorillonite-dominant samples, whereas the high As-Ba- $\mathrm{Rb}$ are characteristic of the opal-dominant ones. The high $\mathrm{Cu}$ and $\mathrm{Nd}$ values, explained by the PC2 loadings, confirm not to have a clear correlation to the dominant mineralogy.
As mentioned before, the distribution of the alteration is not uniform; therefore, the intrusion per se does not fully explain the variations in the concentration of a particular element. Other factors such as the composition of the parental rock, the perlitisation process or percolation of groundwater should also be considered. In any case, the mechanisms of enrichment are constant for some elements, which appear frequently related to a particular mineral phase. Based on these observations, a mineralogical-based approach could be used to estimate the concentration of the target elements in similar samples. The "Chemical impurities" section showed that the differences in element concentration are not strictly related to the variations in particle size. The mineralogical analysis revealed that the mineral composition of a particular fraction size is not the same in the two pits. The PCA results for chemical impurities and the OM index of the size fraction samples were integrated taking those observations into account. The PCA scores and loadings of PC1 and PC2 are shown in Fig. 11b. The spreading of the data points, coloured according to their respective OM values, shows a separation between the montmorillonite- and opal-dominant mineralogy. With comparable results as those for Pit 3, the loadings of the chemical impurities indicate that the montmorillonite-dominant samples have higher $\mathrm{Ti}$ and $\mathrm{Zn}$ concentrations, and the opal-dominant ones have a higher amount of $\mathrm{Ba}$ and $\mathrm{Rb}$. The $\mathrm{Cr}, \mathrm{Fe}$ and $\mathrm{Ni}$ loadings lie perpendicular to the direction of the mineralogical variation. Therefore, they cannot relate with certainty to a mineral phase. 


\section{Loadings PC1}

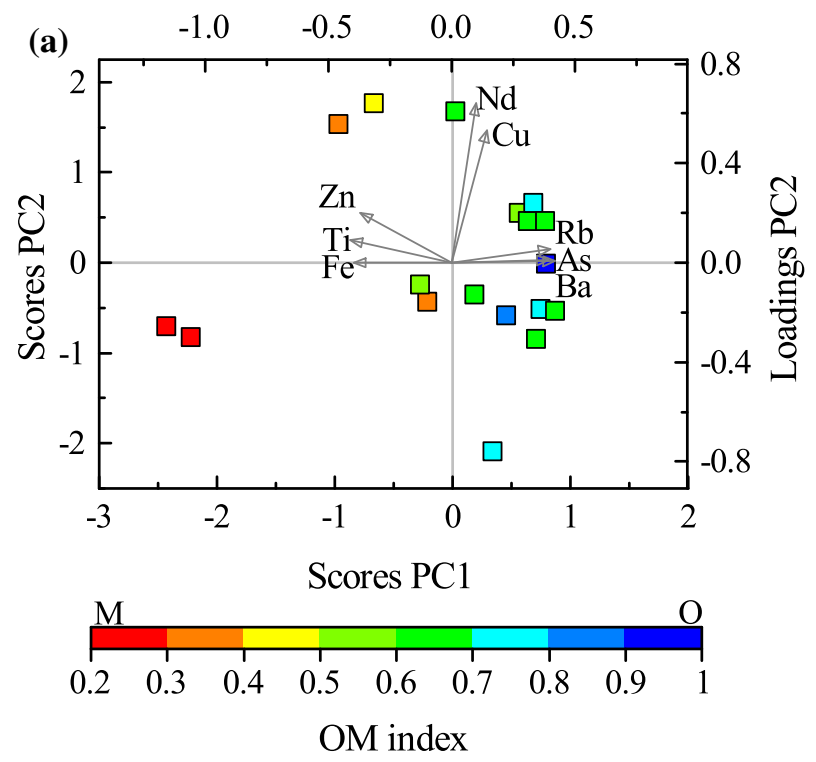

Loadings PC1

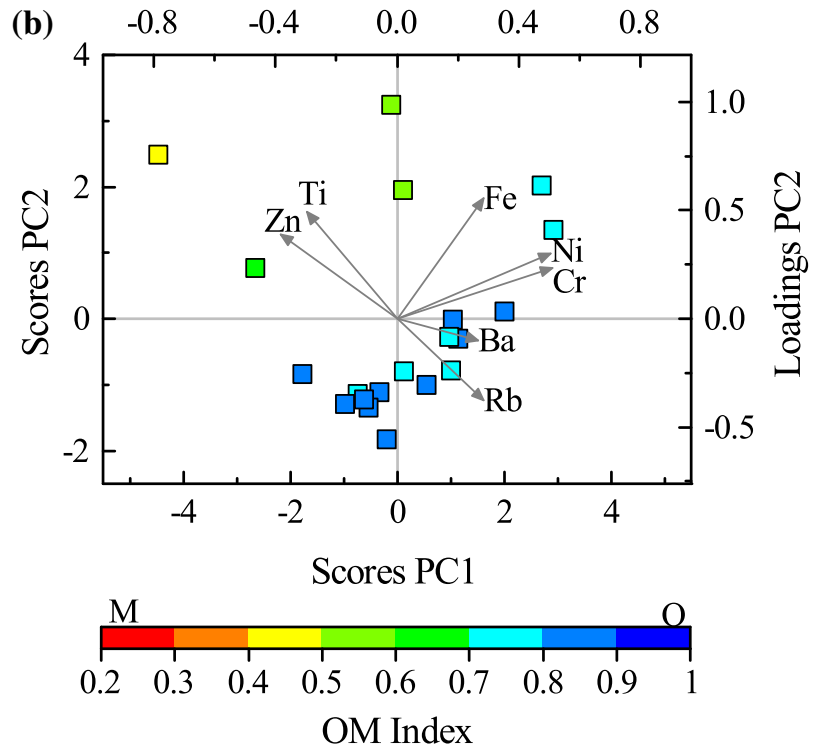

Fig. 11 a Pit 3 integration of the OM index with the variability of chemical impurities as analysed with PCA (scores and loadings of the $\mathrm{PC} 1$ and PC2). The PC1 scores are related to the variations in mineralogy, whereas the loadings indicate the likelihood of elevated concentrations of the chemical impurities. $\mathrm{Pb}, \mathrm{Hg}$ and $\mathrm{Sb}$ not shown for readability; b pits 1 and 2 integration of the OM index with the variability of chemical impurities as analysed with PCA (scores and loadings of the PC1 and PC2). The loadings indicate the likelihood of elevated concentrations of the chemical impurities. $\mathrm{Pb}$ not shown for readability

\section{Opportunities for implementation}

Throughout the analyses, several differences were detected between Pits 1 and 2. Even though it was anticipated that the main factor affecting the quality of the perlite ore was the presence of intrusions from a felsic epithermal system, the elevated concentration of $\mathrm{Fe}, \mathrm{Ni}$, and $\mathrm{Cr}$, especially in Pit 1, indicated an additional source of contaminants. Such source is likely related to volcanic rocks of mafic composition that preceded the formation of the perlite deposit. Moreover, the reduced content of montmorillonite in Pit 1 indicated that locally the influence of the felsic hydrothermal intrusions was limited, which resulted in a lower content of the associated chemical impurities. In the absence of evident in-pit features, such as fractures or changes in colour and texture of the ore, it is difficult to determine whether certain areas of the perlite deposit have more or less influence of the identified sources of contaminants.

In such geological context, the characterisation of the perlite ore using the $\mathrm{OM}$ index provides with a tool to determine the mineralogical composition of the ore, enabling to focus further analysis in the more likely contaminants. The determination of the dominant mineralogy in the perlite ore can be used to estimate the presence of chemical impurities and the expected proportion of fine particles generated during mineral processing. Perlite ores with low OM index can be regarded as influenced mainly by the hydrothermal intrusions, and thus they will be possibly enriched in elements characteristic of felsic epithermal systems; such ores will also produce a larger amount of fine particles due to the increased clay minerals content. In contrast, perlite ores with high OM index will indicate no secondary alteration, with a consequent homogeneous and opal-dominant mineralogy, which during mineral processing will generate a smaller volume of fine particles. In these ores, the type of chemical impurities would be related only to the genesis of the deposit.

These observations provide a framework for the in-pit characterisation of perlite ores, by offering parameters for monitoring and control during the mining and processing activities. As a result, a sensor-based in-pit or on-line approach using of SWIR spectroscopy as a mineral identification technique could be practically implemented. Portable SWIR devices permit the retrieval of data on-site and in real time. Even though the samples used for this study were measured as pressed powders, the results are still valid for on-site point measurements. On the one hand, the segment of the spectra used in the analysis is not influenced by environmental conditions. On the other hand, on-site measurements have the ease of collecting several data points in the form of grids or transects to provide a complete overview of the mine face, becoming even more meaningful than the powder samples.

For the on-site measurement of the $\mathrm{OM}$ index, equal care should be given to the sampling strategy as well as the data processing. The selected mine face should be free of vegetation, animal intervention, disruption by mining 
equipment or substances. The essential steps ensuring the collection a good spectral record are:

1. Basic data collection Gathering of a general description of the pit where the measurements will be gathered, as well as the date, time and environmental conditions (rainy or dry).

2. Survey area selection Definition of a transect along the ripping direction for ore extraction. Description of the selected mine face including its specific location inside the pit, identification of particular features (e.g. fractures, veins, colour) and digital photographs. Division of the transect into segments that are approximately $1 \mathrm{~m}$ width. The spectral measurements will be later collected for every segment covering an area of $1 \mathrm{~m}^{2}$ approx.

3. Spectral data acquisition Preparation of the spectrometer according to the manufacturers specifications for warming-up and calibration. Cleaning of the rock surface for dust and other nuisance. Collection of 5 to 10 point spectral measurements, per every segment of the transect, equally distributed on a surface of approximately $1 \mathrm{~m}^{2}$, ensuring that there is a full contact between the rock surface and the spectrometer

Once all the spectral data is collected, the spectra should be processed before calculation of the OM index:

1. Pre-processing Processing of the data to reflectance and conversion of the wavelengths to micrometres. Graphical evaluation of each spectrum to detect issues or apparent outliers and attempt to explain them. Outliers due to real variations should be kept, outliers due to bad spectra quality, the data point should be discarded.

2. Extraction of spectral parameters The parameters and spectral enhancing methods required for calculating the $\mathrm{OM}$ index are usually available in software dedicated for spectral processing. The first step is the removal of the continuum, followed by the extraction of the $2.2 w$ and $1.4 d$ parameters. For the $2.2 w$ parameter, the shoulders of the absorption must be sought between 2.0 and $2.4 \mu \mathrm{m}$. The $1.4 d$ parameter is calculated as 1 - reflectance at $1.4 \mu \mathrm{m}$.

3. Calculation of the OM index Estimation of the $\mathrm{OM}$ index using Eq. (1) and the parameters previously extracted. Evaluation the OM values for each segment and analysis of the perlite ore variability in the surveyed mine face.

The OM index should be interpreted and used taking into account the overall description of the mine face and the pit. The calculation of the OM index gives a quick estimation of the dominant mineralogy based on spectral data. Its implementation could influence decision making prior to mining, aiming to minimise the associated environmental risks by identification and preferential extraction of lowmontmorillonite ores. Moreover, it could assist in the creation of a smart processing program to maximise resource extraction efficiency, optimise the use of the exploited ore and reduce the generation of waste. That would ensure the production of safe perlite products and a reduction in the environmental impact and the health risks associated with the perlite mining and processing.

\section{Conclusions}

This study has presented a method for the in-pit characterisation the ore variability of perlite in order to predict factors that are deemed as environmental risks in mining and processing. Based on the results, the mineralogical variations in the ore were found to be a major controlling factor when an epithermal system has influenced it. The mineralogical analysis based on infrared (SWIR, MWIR and LWIR) spectroscopy identified opal and montmorillonite as the major constituents in the ore. By establishing the relative proportion of one or the other in the crude ore, it was possible to predict the generation of fine particles and to estimate the concentration of chemical impurities.

The results of particle size analysis and mineralogy showed that perlite ores with an opal-dominant composition produced particles mainly in a preferred size fraction, leading to a smaller volume of fine particles. In contrast, ores composed of a mixture of opal and montmorillonite produced particles distributed more homogeneously along the entire size fraction range. As a consequence, the amount of fine particles was greater than in the opaldominant ore. With regard to the presence of chemical impurities, montmorillonite-dominant ores hosted an elevated concentration of elements characteristic of felsic epithermal systems, whereas the impurities in opal-dominant ores seem to be related to elements from rocks of mafic composition.

The development of the Opal-Montmorillonite (OM) index assisted in the determination of the dominant mineralogy in the ore. This index makes use of infrared spectral data in the SWIR range to indicate whether a perlite sample is opal-dominant or montmorillonite-dominant. Based on this estimation, it could be assessed if the ore is prone to the generation of large volumes of fine particles and the type of chemical impurities likely to be present. This result could be implemented during mining and processing of the perlite ores. With the widespread commercial availability of portable infrared devices, in-pit mineralogical characterisation of the ore could be readily and routinely achieved. This could be utilised for selective mining and as a mechanism for monitoring and control of 
the process. This approach would have a positive impact on reduction of generation of waste and the production of safe perlite products.

Acknowledgements The authors wish to thank Imerys Ltd., UK and Turkey, for the access to the samples. This work has been financially supported by the European FP7 project Sustainable Technologies for Calcined Industrial Minerals in Europe (STOICISM), grant NMP2LA-2012-310645. The authors would like to thank the anonymous reviewers for their constructive comments that greatly contributed to improving this paper.

Open Access This article is distributed under the terms of the Creative Commons Attribution 4.0 International License (http://crea tivecommons.org/licenses/by/4.0/), which permits unrestricted use, distribution, and reproduction in any medium, provided you give appropriate credit to the original author(s) and the source, provide a link to the Creative Commons license, and indicate if changes were made.

\section{References}

Allen RL (1988) False pyroclastic textures in altered silicic lavas, with implications for volcanic-associated mineralization. Econ Geol 83(7):1424-1446. https://doi.org/10.2113/gsecongeo.83.7. 1424

Baba A, Sozbilir H (2012) Source of arsenic based on geological and hydrogeochemical properties of geothermal systems in Western Turkey. Chem Geol 334:364-377. https://doi.org/10.1016/j. chemgeo.2012.06.006

Barker JM, Santini K (2006) Industrial minerals and rocks, book section perlite. In: Society for mining, metallurgy, and exploration, 7 th edition edition. ISBN 9780873352338

Bennett SM (2013) 2013 minerals year book - perlite [advance release]. http://minerals.usgs.gov/minerals/pubs/commodity/per lite/myb1-2013-perli.pdf

Blunt WG (1994) Characteristics of perlite filter aids. In: Industrial minerals '94: sixth Canadian conference on markets for industrial minerals, Canadian conference on markets for industrial minerals, Willowdale, Ont. Blendon Information Services

Chester R, Elderfield H (1968) The infrared determination of opal in siliceous deep-sea sediments. Geochim Cosmochim Acta 32(10):1128-1140. https://doi.org/10.1016/00167037(68)90113-0

Christidis GE (1998) Comparative study of the mobility of major and trace elements during alteration of an andesite and a rhyolite to bentonite, in the islands of milos and kimolos, aegean, greece. Clays Clay Miner 46(4):379-399. https://doi.org/10.1346/ CCMN.1998.0460403

Clark RN, Swayze GA, Wise R, Livo KE, Hoefen TM, Kokaly RF, Sutley SJ (2007) Usgs digital spectral library splib06a. URL http://speclab.cr.usgs.gov/spectral.lib06/ds231/datatable.html

Clarke DS (1989) The trace element geochemistry of vein material in epithermal systems: significance for exploration. In 11th New Zealand Geothermal Workshop, pp 139-142. University of Auckland

Cooper WC, Sargent EN (1986) Study of chest radiographs and pulmonary ventilatory function in perlite workers. J Occup Environ Med 28(3):199-206 ISSN 0096-1736

CSIRO (2007) The spectral geologist software suite. URL http:// www.thespectralgeologist.com/
Davidson CI, Phalen RF, Solomon PA (2005) Airborne particulate matter and human health: a review. Aerosol Sci Technol 39(8):737-749. https://doi.org/10.1080/02786820500191348

Elmes PC (1987) Perlite and other 'nuisance' dusts. J R Soc Med 80(7):403-404. https://doi.org/10.1177/014107688708000703

FAO (2006) Combined compendium of food additive specifications, volume 4 of Analytical methods, test procedures and laboratory solutions used by and referenced in the food additive specifications. Food and Agriculture Organization of the United Nations, Rome. ISBN 92-5-105569-6

Farmer VC (1974) The layer silicates, volume Monograph 4, book section 15, pp 331-364. Mineralogical Society. ISBN 0903056054

Fink JH (1983) Structure and emplacement of a rhyolitic obsidian flow: Little glass mountain, medicine lake highland, northern california. Geol Soc Am Bull 94(3):362-380. https://doi.org/10. 1130/0016-7606(1983)94<362:saeoar $>2.0 . c 0 ; 2$

Gupta RP (2003) Remote sensing geology, 2nd edn. Springer, Berlin. https://doi.org/10.1007/978-3-662-05283-9

Hackwell JA, Warren DW, Bongiovi RP, Hansel SJ, Hayhurst TL, Mabry DJ, Sivjee MG, Skinner JW (1996) LWIR/MWIR imaging hyperspectral sensor for airborne and ground-based remote sensing. In SPIE 2819, volume 2819 of imaging spectrometry II, pp 102-107. https://doi.org/10.1117/12.258057

Hunt GR (1977) Spectral signatures of particulate minerals in the visible and near infrared. Geophysics 42(3):501-513. https://doi. org/10.1190/1.1440721

Karacik Z, Yilmaz Y, Pearce J (2007) The dikili-candarli volcanics, western turkey: magmatic interactions as recorded by petrographic and geochemical features. Turk J Earth Sci 16:493-522 ISSN ISSN: 1300-0985

Maisanaba S, Pichardo S, Puerto M, Gutirrez-Praena D, Camen AM, Jos A (2015) Toxicological evaluation of clay minerals and derived nanocomposites: a review. Environ Res 138:233-254. https://doi.org/10.1016/j.envres.2014.12.024

Maxim LD, Niebo R, McConnell EE (2014) Perlite toxicology and epidemiology - a review. Inhal Toxicol 26(5):259-270. https:// doi.org/10.3109/08958378.2014.881940

Milkey RG (1960) Infrared spectra of some tectosilicates. Am Mineral 45(9-10):990-1007 ISSN 0003-004X

Moenke HHW (1974) Silica, the Three-dimensional Silicates, Borosilicates and Beryllium Silicates, volume Monograph 4, book section 16, pp 365-382. Mineralogical Society. ISBN 0903056054

Noh JH, Boles JR (1989) Diagenetic alteration of perlite in the Guryongpo area, Republic of Korea. Clays Clay Miner 37(1):47-58. https://doi.org/10.1346/Ccmn.1989.0370106

OIV (2017) International oenological codex

Parke S (1974) Glasses, volume Monograph 4, book section 21, pp 583-513. Mineralogical Society. ISBN 0903056054

Petit JC, Dellamea G, Dran JC, Magonthier MC, Mando PA, Paccagnella A (1990) Hydrated-layer formation during dissolution of complex silicate-glasses and minerals. Geochim Cosmochim Acta 54(7):1941-1955. https://doi.org/10.1016/00167037(90)90263-K

Ray A, Sriravindrarajah R, Guerbois JP, Thomas PS, Border S, Ray HN, Haggman J, Joyce P (2007) Evaluation of waste perlite fines in the production of construction materials. J Therm Anal Calorim 88(1):279-283. https://doi.org/10.1007/s10973-006$8107-\mathrm{z}$

Sampatakakis S, Linos A, Papadimitriou E, Petralias A, Dalma A, Papasaranti ES, Christoforidou E, Stoltidis M (2013) Respiratory disease related mortality and morbidity on an island of greece exposed to perlite and bentonite mining dust. Int J Environ Res Public Health 10(10):4982-95. https://doi.org/10.3390/ ijerph10104982 
Shackley D, Allen MJ (1008) Perlite and the perlite industry. Miner Ind Int 13-22:1992

Silberman ML, Berger BR (1985) Relationship of trace-element patterns to alteration and morphology in epithermal preciousmetal deposits, volume 2 of Reviews in Economic Geology, book section 9, pp 203-232. Society of Economic Geologist, El Paso, USA

Stein HA, Murdock JB (1955) The processing of perlite. Calif J Mines Geol 51(2):105-116

Thompson AJB, Hauff PL, Robitaille AJ (1999) Alteration mapping in exploration: application of short-wavelength infrared spectroscopy. SEG Newslett 39(1):13
USEPA (1995) Perlite manufacturing. https://www3.epa.gov/ ttnchie1/ap42/ch11/

USPC (2012) Food chemicals codex, 28-06-2016. http://app.knovel. com/hotlink/toc/id:kpFCCE001Q/food-chemicals-codex/foodchemicals-codex

Yanev Y (2008) Geology of the eastern rhodopes perlite deposits (bulgaria): a review. In: 6th International conference and exhibition on perlite, pp 177-195

Yilmaz H (2002) Ovacik gold deposit: an example of quartz-adulariatype gold mineralization in Turkey. Econ Geol Bull Soc Econ Geol 97(8):1829-1839. https://doi.org/10.2113/97.8.1829 